\title{
Liquefaction hazard assessment and ground failure probability analysis in the Kathmandu Valley of Nepal
}

\author{
Mandip Subedi ${ }^{*}$ and Indra Prasad Acharya
}

\begin{abstract}
During the 2015 Gorkha Earthquake $\left(M_{w} 7.8\right)$, extensive soil liquefaction was observed across the Kathmandu Valley. As a densely populated urban settlement, the assessment of liquefaction potential of the valley is crucial especially for ensuring the safety of engineering structures. In this study, we use borehole data including SPT-N values of 410 locations in the valley to assess the susceptibility, hazard, and risk of liquefaction of the valley soil considering three likely-to-recur scenario earthquakes. Some of the existing and frequently used analysis and computation methods are employed for the assessments, and the obtained results are presented in the form of liquefaction hazard maps indicating factor of safety, liquefaction potential index, and probability of ground failure $\left(P_{G}\right)$. The assessment results reveal that most of the areas have medium to very high liquefaction susceptibility, and that the central and southern parts of the valley are more susceptible to liquefaction and are at greater risk of liquefaction damage than the northern parts. The assessment outcomes are validated with the field manifestations during the 2015 Gorkha Earthquake. The target SPT-N values ( $N_{\text {improved }}$ ) at potentially liquefiable areas are determined using back analysis to ascertain no liquefaction during the aforesaid three scenario earthquakes.
\end{abstract}

Keywords: Liquefaction, SPT-N, Hazard, Risk, Ground improvement, Kathmandu Valley

\section{Introduction}

Soil liquefaction is one of the common seismic consequences that frequently lead to significant structural damage during earthquakes (Setiawan et al. 2017). Different parts of the world have observed liquefactioninduced ground as well as structural damages in the past in loose, saturated sands and other granular soils (Setiawan et al. 2018). Surface manifestations of liquefaction have been well recorded during various earthquake events, such as Nepal-Bihar Earthquake (1934, Nepal), Alaska Earthquake (1964, USA), Niigata Earthquake (1964, Japan), Loma Prieta (1989, USA), Kobe Earthquake (1995, Japan), Chi-Chi Earthquake (1999, Taiwan), Bhuj Earthquake (2001, India), Chile Earthquake (2010),

*Correspondence: mandip.072phce104@ioe.edu.np Department of Civil Engineering, Pulchowk Campus, loE, Tribhuvan University, Lalitpur, Nepal
Emilia-Romagna (2012, Italy) and Gorkha Earthquake (2015, Nepal) (Ansal and Tönük 2007; Novikova et al. 2007; Sharma et al. 2018; etc.). All these manifestations have led to an understanding that liquefaction occurs mostly in fine loose and saturated silty sands, low-plastic silty clays, and non-plastic silts as a result of substantial loss of material shear strength (Jalil et al. 2021). It is also witnessed that not only the larger magnitude earthquakes (i.e., $M_{\mathrm{w}}>7$ ) but moderate earthquakes (i.e., $M_{\mathrm{w}}=5$ to 6) can also induce liquefaction (Boulanger and Idriss 2014).

With an approximate population of 5 million and a population density of $13,225 / \mathrm{km}^{2}$, the Kathmandu Valley (KMC 2011), is one of the fastest urbanizing cities in South Asia. Many urban settlements within the valley have recently exhibited rapid developments on their outskirts (Chaulagain et al. 2016). As a seismically active area in the Nepal Himalaya, the Kathmandu Valley has a long history of large earthquakes. The valley experiences 
comparatively heavy damage during earthquakes because of its ground features, which are composed of lacustrine sediments and have high earthquake wave amplification capacity (Chaulagain et al. 2016). The lacustrine deposit also consists of near-surface fine to coarse granular material layers at different locations with considerably high groundwater tables, which may potentially liquefy during earthquake shaking (Okamura et al. 2015; Sharma et al. 2019).

To ensure the seismic safety of engineering structures in earthquake-prone regions, it is vital to determine the liquefaction potential of ground material (Naghizadehrokni et al. 2018). So far in the Kathmandu Valley, there are only a few case studies related to liquefaction hazard assessment including UNDP (1994), JICA (2002), and Piya (2004). UNDP (1994) and Piya (2004) adopted similar analysis techniques, but the former followed the qualitative analysis method for determining the liquefaction score, while the latter used borehole data to verify the qualitative analysis results quantitatively. The qualitative assessment considered the surficial geology and geotechnical characteristics such as SPT-N value, depth of groundwater table, particle size distribution, Atterberg limit etc. The liquefaction hazard maps developed by UNDP (1994) and Piya (2004) contradict those prepared by JICA (2002), which reported that most of the areas in the Kathmandu Valley are less susceptible to liquefaction. All these three studies are argued to have been erroneous, incomplete, and to have underestimated the liquefaction susceptibility of the Kathmandu Valley (e.g., Gautam et al. 2017; KC et al. 2020; Sharma et al. 2016, 2018, 2019; Subedi et al. 2021). Thus, it is imperative to revise the liquefaction study in the valley through reliable analysis and assessment methods in order to update the existing liquefaction hazard maps and verify them with the field evidence from the 2015 Gorkha Earthquake.

In this study, we use borehole data with SPT-N values of 410 locations in the Kathmandu Valley and perform liquefaction analysis considering three likelyto-recur earthquakes viz. $M_{\mathrm{w}} 7.8(0.18 \mathrm{~g}), M_{\mathrm{w}} 8.0(0.30 \mathrm{~g})$ and $M_{\mathrm{w}} 8.4(0.36 \mathrm{~g})$. The liquefaction analysis is done in terms of factor of safety (FOS) against liquefaction, liquefaction potential index (LPI), and probability of ground failure $\left(P_{\mathrm{G}}\right)$. For the factor of safety against liquefaction for each soil layer, we use stress-based technique proposed by Idriss and Boulanger (2008) while for estimating the liquefaction potential index, we use Iwasaki et al. (1982) method. Likewise, for the quantitative evaluation, we refer to Li et al. (2006) and determine the liquefaction-induced probability of ground failure $\left(P_{\mathrm{G}}\right)$. The validity of outcomes of the simplified procedure for liquefaction analysis in FOS, LPI, and $P_{\mathrm{G}}$ is carried out with 25 observed liquefaction cases during the 2015 Gorkha
Earthquake. Additionally, the target SPT-N values $\left(N_{i m-}\right.$ proved) at potentially liquefiable areas are determined using backward analysis, ascertaining no liquefaction during the aforementioned three seismic scenarios.

\section{Study area \\ Geology and seismicity}

The Kathmandu Valley deposit consists of soft sediment of mainly lacustrine and fluvial origin with a maximum depth of about $650 \mathrm{~m}$ at the center (Sakai 2001). Typically, the sediment deposits consist of mixtures of gravel, sand, silt, and clay (Mugnier et al. 2011; Paudyal et al. 2013; Sharma et al. 2016; Subedi et al. 2018) with a shallow groundwater table (Pathak et al. 2009; Shrestha et al. 2016). Almost all the flood plains of the valley constitute potential liquified sites (Gautam et al. 2017; Sharma et al. 2019; Subedi et al. 2018). The schematic geological map of the valley is shown in Fig. 1.

Nepal lies in one of the most seismically active regions of the world, with a long history of earthquakes and experiences at least one major quake in about 100 years (Thapa 2018; KC et al. 2019). As a soft lacustrine deposit, the Kathmandu Valley ground is prone to amplified shakings during earthquakes, which is corroborated during many earthquakes of the past, such as in 1803, 1833, 1934, 1960, 1988 and 2015 (Dixit et al. 2013; Gautam et al. 2017). Based on the shaking record of the valley as well as other parts of Nepal of recent earthquakes, the Department of Urban Development and Building Construction (DUDBC) has published a new seismic hazard map of Nepal (NBC 2020), which indicates that the peak ground acceleration during an earthquake may reach $0.36 \mathrm{~g}$ to $0.4 \mathrm{~g}$ during probabilistic seismic hazard analysis (PSHA) with a $10 \%$ probability of exceedance over a 50-year study period. This is more than twice the maximum acceleration recorded during the $M_{\mathrm{w}} 7.8,2015$ Gorkha Earthquake (i.e., $0.18 \mathrm{~g}$ as recorded in the Kathmandu Valley).

\section{Geotechnical conditions}

The liquefaction potential of sediments can be predicted using subsurface sediment properties and lithological units in a given area (Bansal and Nath 2011; Kramer 1996). For this, total 410 borehole data with standard penetration tests (SPT) from different locations were used for the study. Among them, primary data were assessed and investigated with 10 borehole data; 5 boreholes at liquefaction sites of 2015 during the Gorkha Earthquake and 5 boreholes at the core city area. Rest of the data were obtained from geotechnical investigation reports of 400 locations in the valley availed by local soil laboratories and SAFER database prepared by the University of Bristol (Gilder et al. 2019). 


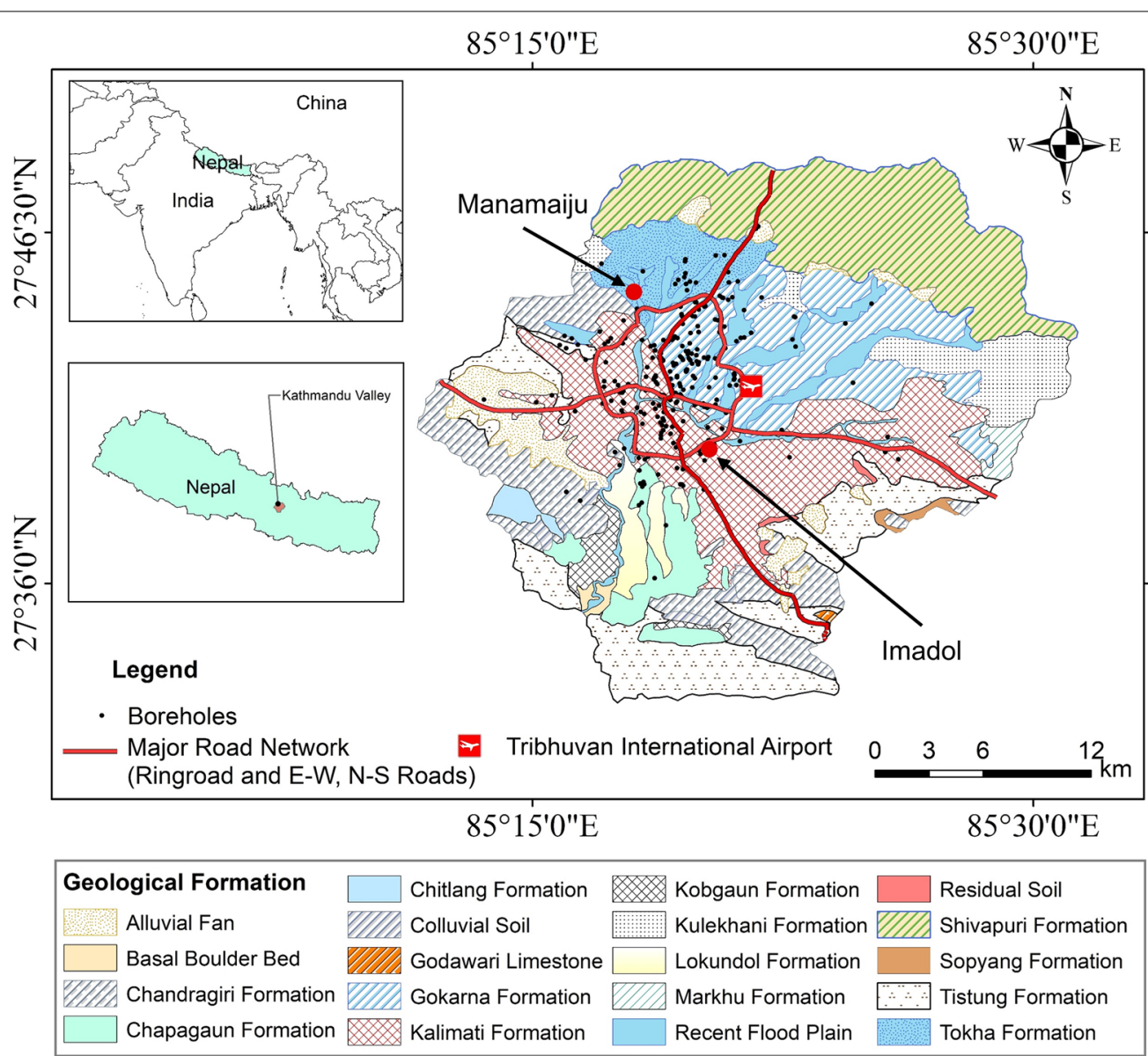

Fig. 1 Kathmandu Valley area and its geological formations (modified after Dhital 2015) together with the locations of the boreholes used in the study and locations of Manamaiju and Imadol where liquefaction was manifested during the 2015 Gorkha Earthquake (refer Fig. 2)

The geotechnical investigation includes standard penetration tests and particle size distribution (sieve and hydrometer analyses), Atterberg's limits, dry unit weight, natural moisture content, triaxial tests, and ring shear tests. Two typical borehole logs of the liquefied sites (Manamaiju and Imadol) during the 2015 Gorkha Earthquake are shown in Fig. 2 along with pictures of observed liquefaction. At Manamaiju (Fig. 2a), the SPT-N values are less than 10 up to the depth of $6 \mathrm{~m}$ and less than $15 \mathrm{up}$ to the depth of $12 \mathrm{~m}$ while in case of Imadol (Fig. 2b), the SPT-N values are less than 10 up to the depth of $15 \mathrm{~m}$. At both locations, the soil types are mostly low plastic silt (ML) and silty sand (SM). Low SPT-N values, shallow groundwater table $(1.5 \mathrm{~m})$ and sand-silt type soil composition preliminarily justify the possibility of soil liquefaction during earthquake shaking.

Figure 3 is a 15 times vertically exaggerated (i.e., $\mathrm{H}: \mathrm{V}=1: 15) 3 \mathrm{D}$ lithological model of the study area created in Rockworks 2016 with a solid modeling algorithm 'litho blend' using the lithological database of the boreholes ranging in depth from 15 to $20 \mathrm{~m}$ at an interval of $1.5 \mathrm{~m}$. From this 3D model, it is understood that the subsoil of the study area comprises clay and silt layers in a few meters' surficial depth, and with the increase in depth, it has sand and silty sand layers.

Kathmandu Valley subsoil possesses heterogeneous lithology, soil variability and exposure to different overburden stresses. Standard distribution system is used to provide a general characterization for the Kathmandu soil typology. The number of data (n), minimum value, maximum value, mean value $(\mu)$, standard deviation $(\sigma)$, and coefficient of variation $(\mathrm{COV})$ were calculated for analyzing variability and statistical analysis, as shown in Table 1. Likewise in Fig. 4, depth-wise variation of geotechnical parameters of valley soil is presented. An analysis of the borehole log data indicates that about $85 \%$ of the borehole locations have SPT-N values less than 20 while more than $50 \%$ have SPT-N values below 10 , especially at shallow depths in the core area of the valley. Moreover the average SPT-N value of Kathmandu 


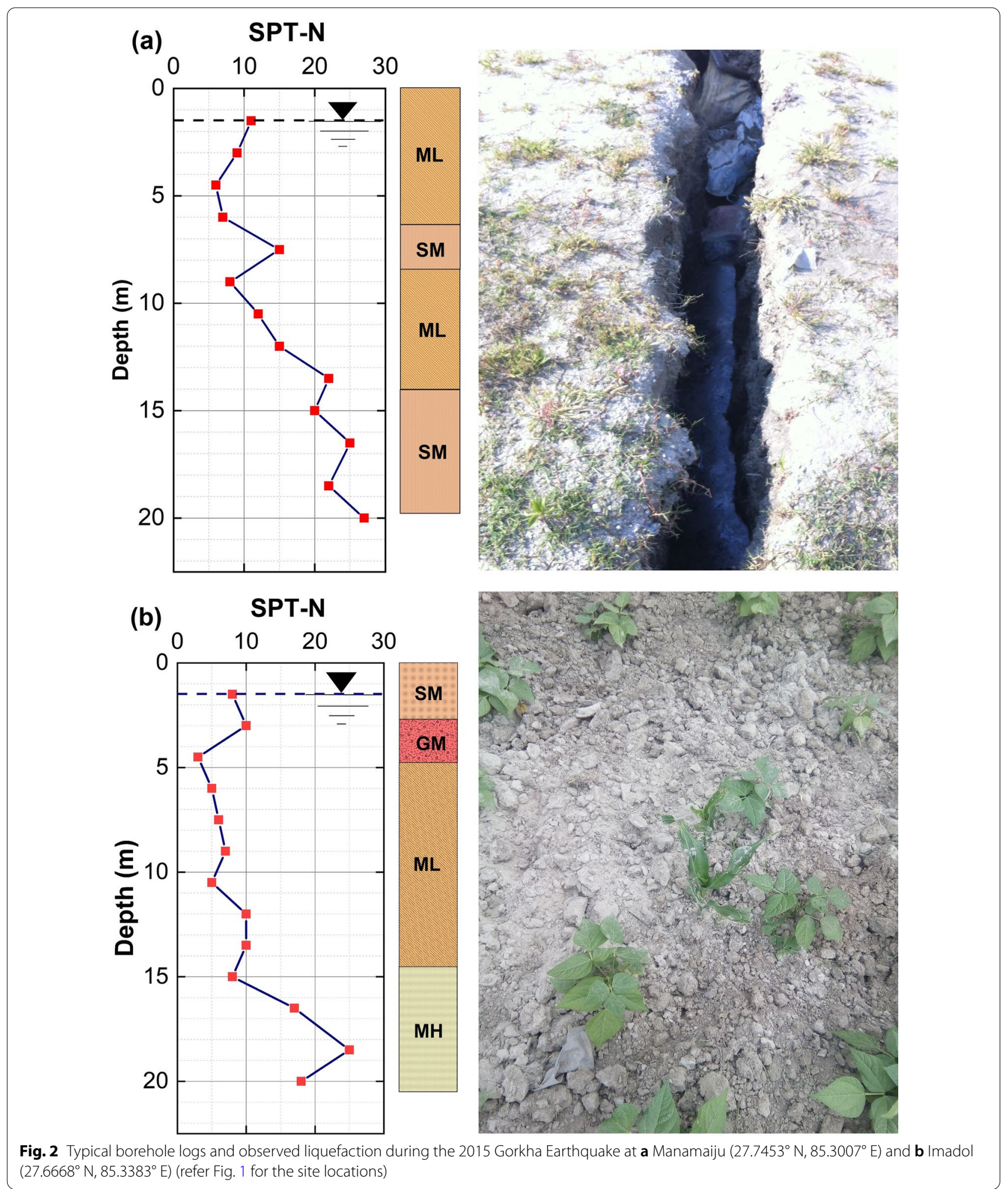

soil at depths $1.5 \mathrm{~m}, 3 \mathrm{~m}, 6 \mathrm{~m}, 9 \mathrm{~m}$ and $15 \mathrm{~m}$ are 12, 15, fines content (FC) with depth in Kathmandu soils is 18, 20 and 23, respectively, with overall $\mu=15, \sigma=11$, shown in Fig. 4b. The value of FC ranges from 0 to $100 \%$ and $\mathrm{COV}=71.87 \%$ (Fig. 4a). Similarly, the variation of with a mean of 52.24, standard deviation of 36.69 , and 


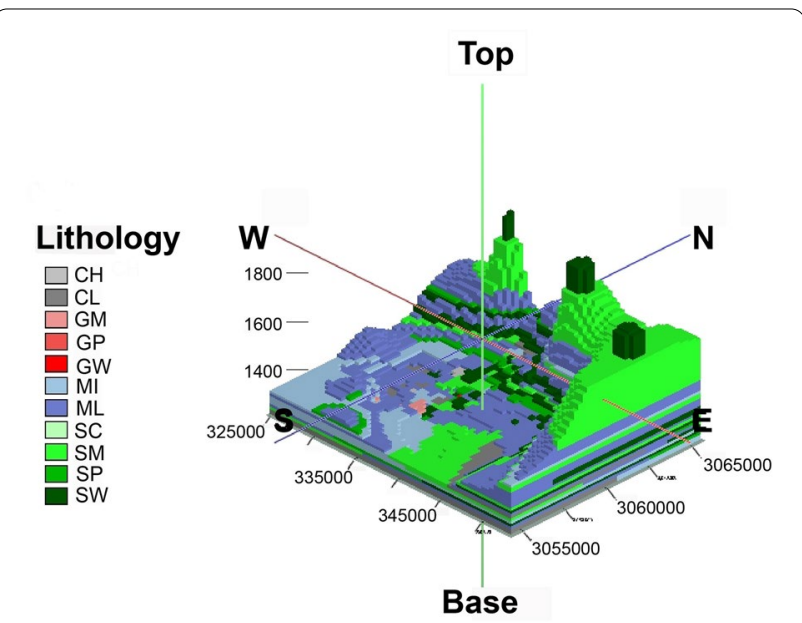

Fig. 3. 15 times vertically exaggerated $3 \mathrm{D}$ lithological model of the Kathmandu Valley created in Rockworks 2016 (The lithology descriptions are $\mathrm{CH}$ : high plastic clay, CL: low plastic clay, GM: silty gravel, GP: poorly graded gravel, GW: well-graded gravel, MI: intermediate plastic silt, ML: low plastic silt, SC: clayey sand, SM: silty sand, SP: poorly graded sand, and SW: well-graded gravel)

a coefficient of variation of $70.24 \%$, which means most parts of the valley have low FC in shallow depths. For most soils in the Kathmandu Valley, the plasticity index (PI) values range from 10 to $20 \%(\mu=15.13, \sigma=6.26$, and $\mathrm{COV}=41.34 \%)$ as shown in Fig. $4 \mathrm{c}$. The average LL and PI values are found to be $44.29 \%$ and $15.13 \%$ (Table 1), which clearly shows the abundance of medium plasticity soils in the Kathmandu Valley. Furthermore, the specific gravity $\left(G_{\mathrm{s}}\right)$ of soil is between 1.89 and $2.89(\mu=2.59$, $\sigma=0.15$, and $\mathrm{COV}=5.79 \%$ ) (Fig. $4 \mathrm{~d}$ ). The average value of $G_{\mathrm{s}}$ is 2.59 which indicates higher content of silty sand (which is vulnerable to liquefaction) in the valley. It is of interest to note that the lower value of SPT-N, abundance of sandy and silty soils with low fines content and low specific gravity support the soil liquefaction vulnerability in the Kathmandu Valley.

Generally, cohesionless sands and coarse silts to low plasticity fines are found to be susceptible to liquefaction. The Kathmandu Valley soil is predominated by dark grey sandy silts followed by low to medium plasticity silts ranging into low to medium plasticity clays. Plotting the data acquired from borehole logs in the particle size distribution chart with liquefaction range given out by Tsuchida and Hayashi (1972) (Fig. 5a), it is illustrated that most of the soils from the Kathmandu Valley are liquifiable suggesting that the valley soil is highly susceptible to liquefaction. Figure $5 \mathrm{~b}$ depicts the plasticity map of all cohesive soils used in the analysis, based on Casagrande (1947). The result ensures that fine-grained soils are mostly silt rather than clays. This finding is crucial for liquefaction researchers, as low plasticity silts are more vulnerable to earthquake motion (Bray and Sancio 2006). Seed et al. (2003) proposed liquefaction susceptibility requirements, represented in the same figure.

\section{Hydrological conditions}

Groundwater is a crucial factor for soil liquefaction and swelling of extremely fine sediments, making the depth to the groundwater table critical in assessing the extent of water concentration in-situ sediments (Yilmaz and Bagci 2006). The shallow groundwater level reduces the effective confining stress at any depth, making liquefaction more likely during an earthquake (Ayele et al. 2021; Nath et al. 2014). The groundwater table study was conducted using data from two sources, i.e. borehole log information and groundwater table map prepared by Shrestha et al. (2016). For this, groundwater map of monsoon season (by Shrestha et al. 2016) and borehole locations were overlaid in ArcGIS. Moreover, groundwater depths for all borehole locations were extracted from the map and compared with the observed groundwater depths during borehole tests. Finally, the worst-case scenario for liquefaction study, i.e., shallow groundwater level, was chosen for all boreholes from the above two data sources. The spatial map showing the maximum groundwater level of Kathmandu Valley is shown in Fig. 6. Groundwater in the valley is found at shallow depths ranging from 0.5 to

Table 1 A statistical overview of the geotechnical properties of Kathmandu Valley soils

\begin{tabular}{|c|c|c|c|c|c|c|}
\hline Property & $\begin{array}{l}\text { Number of data } \\
\text { (n) }\end{array}$ & Min & Max & Mean $(\mu)$ & $\begin{array}{l}\text { Standard deviation } \\
(\sigma)\end{array}$ & $\operatorname{cov}(\%)$ \\
\hline Specific gravity, $G_{s}$ & 302 & 1.89 & 2.89 & 2.59 & 0.15 & 5.79 \\
\hline Plastic limit, PL (\%) & 239 & 15.2 & 50.98 & 29.12 & 7.84 & 26.91 \\
\hline Liquid limit, LL (\%) & 239 & 22.8 & 69.12 & 44.29 & 11.29 & 25.49 \\
\hline Plasticity index, PI (\%) & 239 & 1.73 & 34 & 15.13 & 6.26 & 41.34 \\
\hline Standard penetration test, (SPT-N) & 1167 & 0 & 50 & 15 & 11 & 71.87 \\
\hline Fines content, FC (\%) & 933 & 0 & 100 & 52.24 & 36.69 & 70.24 \\
\hline
\end{tabular}



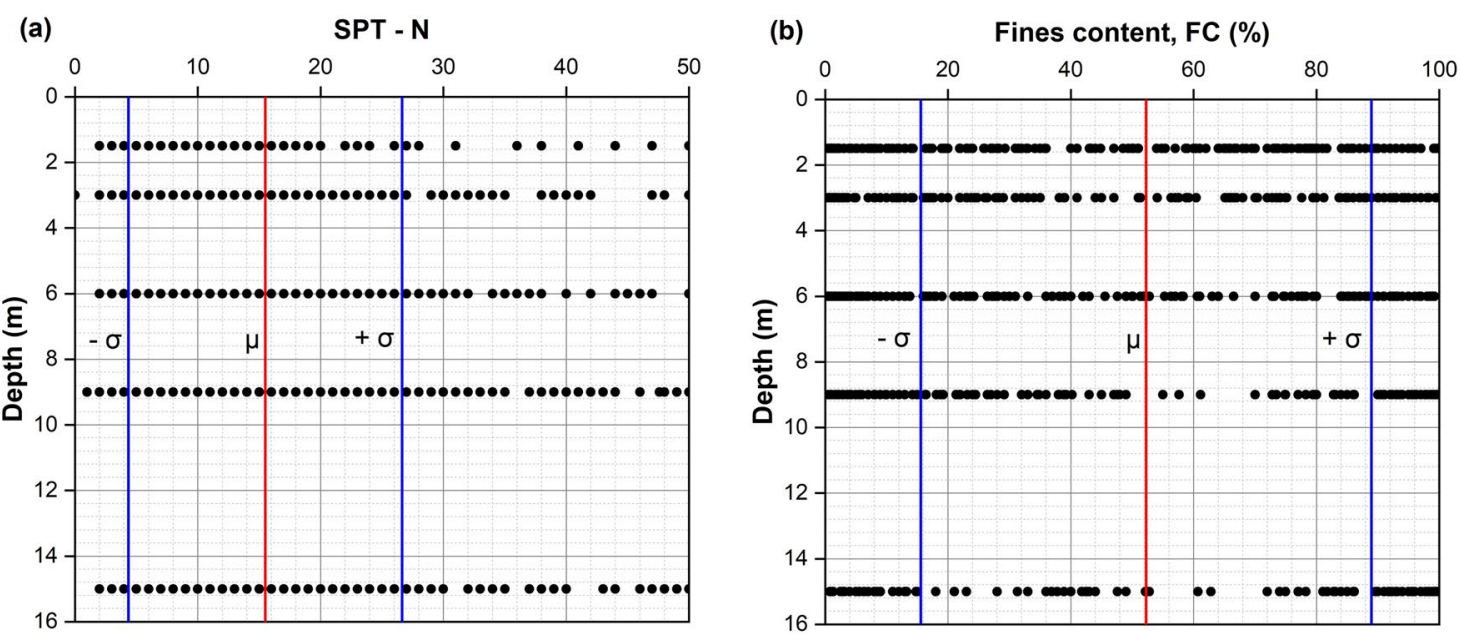

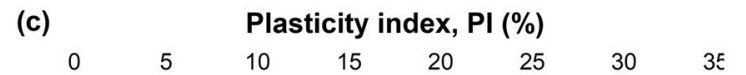

(d)
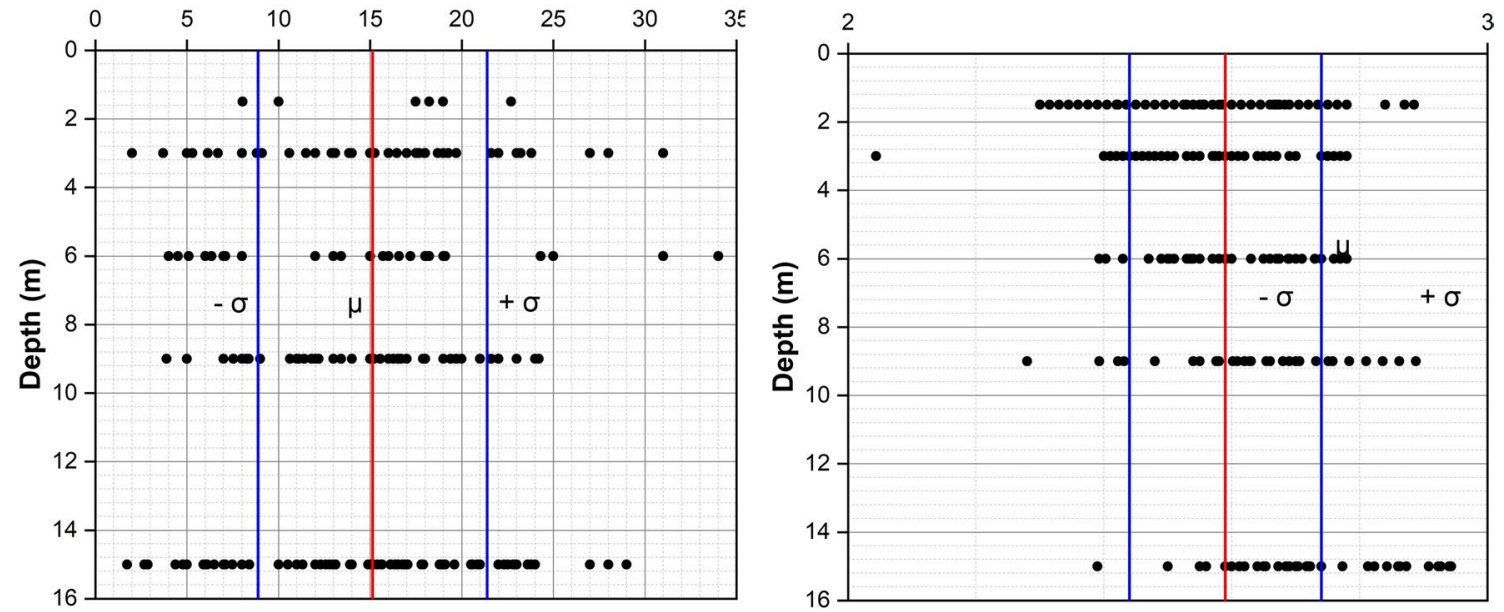

Fig. 4 Depthwise distribution of a SPT-N, b fines content (FC), c plasticity index (PI), and $\mathbf{d}$ specific gravity $\left(G_{S}\right)$ showing mean $(\mu)$ and standard deviation $(\sigma)$ of the data

$5 \mathrm{~m}$ below the ground surface, which attributes the Kathmandu soil to be highly susceptible to liquefaction during seismic events.

\section{Methodology}

As also stated elsewhere above, the liquefaction analysis was conducted for three likely-to-recur scenario earthquakes of magnitudes $M_{\mathrm{w}} 7.8, M_{\mathrm{w}} 8.0$, and $M_{\mathrm{w}} 8.4$ considering peak ground acceleration (PGA) of $0.18 \mathrm{~g}, 0.30 \mathrm{~g}$ and $0.36 \mathrm{~g}$ respectively using existing standards and frequently used analysis and computation methods.

The PGAs and earthquake magnitudes were taken from three standard seismic hazard assessments conducted for the Kathmandu Valley. JICA (2002) reported a PGA of $0.3 \mathrm{~g}$ for the scenario earthquake of $M_{\mathrm{w}} 8.0$ with a $10 \%$ probability of exceedance in 50 years (i.e., return period of 475 years) in the Kathmandu Valley. A PGA of $0.18 \mathrm{~g}$ was observed in the valley during the $M_{\mathrm{w}} 7.8$,
2015 Gorkha Earthquake. After the 2015 Gorkha Earthquake, NBC (2020) has recommended an earthquake of $M_{\mathrm{w}} 8.4$ with a PGA of $0.36 \mathrm{~g}$ for the Kathmandu Valley. All these recommended scenarios were used in the analysis of liquefaction susceptibility in terms of factor of safety (FOS), liquefaction potential index (LPI) and probability of ground failure $\left(P_{\mathrm{G}}\right)$. These parameters were obtained using standard procedures as described in the below sections. The obtained result data were interpolated in ArcGIS using inverse distance weighting (IDW) method and presented as spatial zonation maps in terms of the FOS, LPI and $P_{\mathrm{G}}$. Moreover, graphical and statistical visualizations were prepared using OriginPro. Finally, the target SPT-N values $\left(N_{\text {improved }}\right)$ at potentially liquefiable areas were assessed using back analysis to ascertain no liquefaction during the aforementioned three scenario earthquakes. 

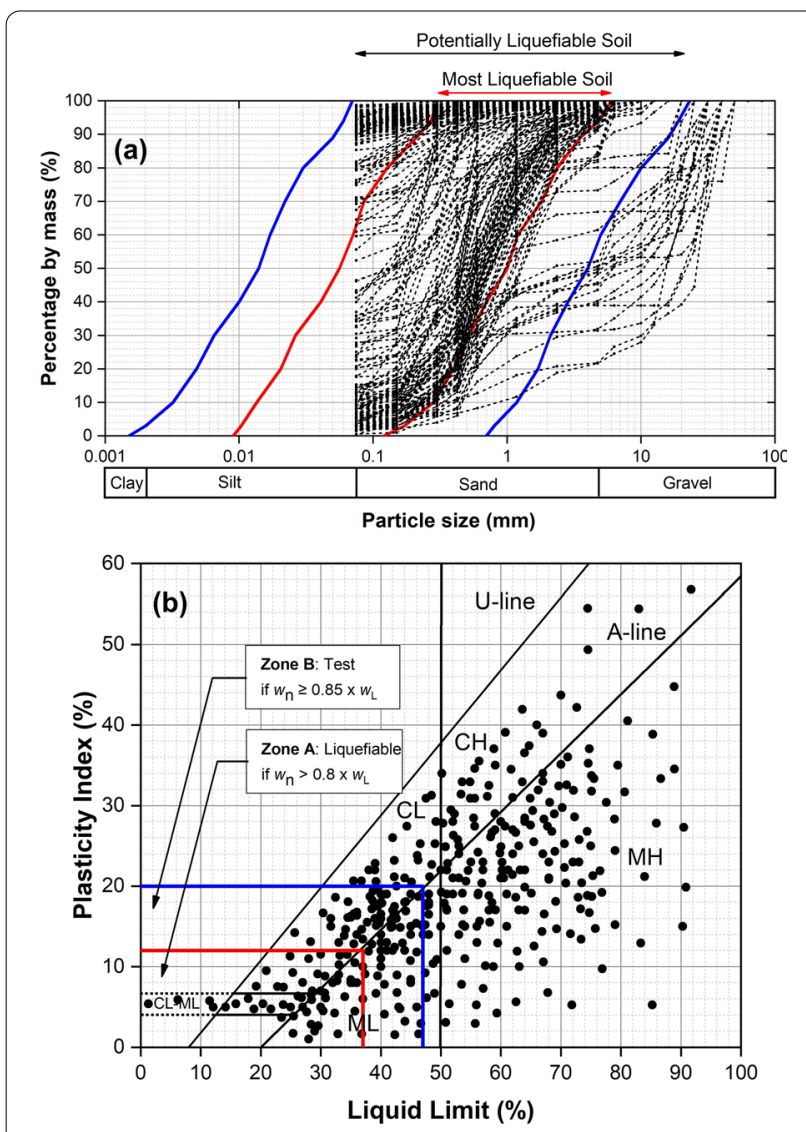

Fig. 5 a Particle size distribution graph of Kathmandu soils with a demarcation of liquefiable soils suggested by Tsuchida and Hayashi (1972), b Casagrande's plasticity chart with liquefaction criteria given by Seed et al. (2003)

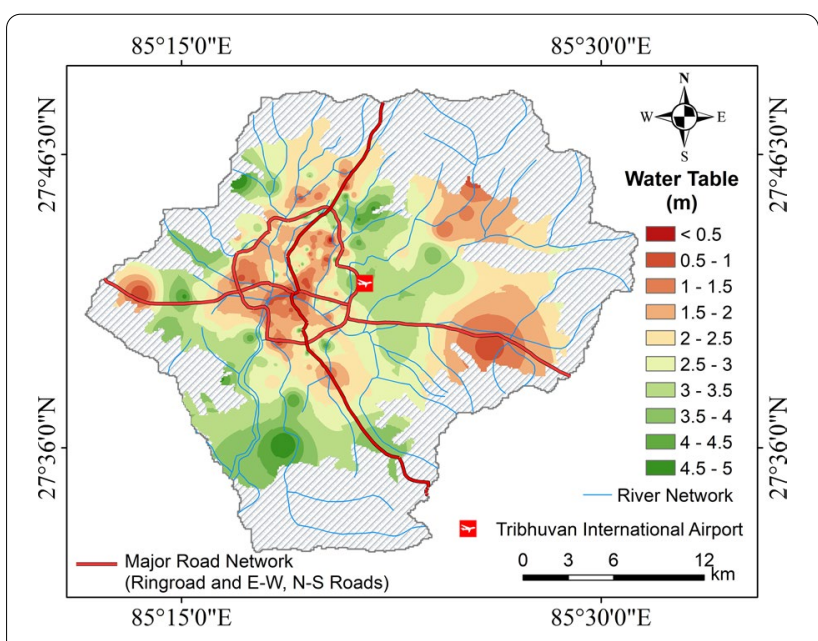

Fig. 6 Spatial mapping of the maximum groundwater level obtained by analyzing borehole data and map by Shrestha et al. (2016)

\section{Determination of the factor of safety (FOS)} against liquefaction

Several methods based on cone penetration test (CPT), shear wave velocity and cyclic loading test (Bolton Seed et al. 1985; Robertson and Wride 1998; Onder Cetin et al. 2004; Moss et al. 2006; Idriss and Boulanger 2008) are used to do accurate liquefaction potential assessment. However, as the CPT, shear wave velocity test, and cyclic loading test are not commonly practiced in Nepal, the liquefaction potential assessment in the valley largely relies on borehole data with SPT-N. In this regard, a method developed by Idriss and Boulanger (2008) is adopted in this study to perform an analysis of the factor of safety (FOS) against liquefaction. Idriss and Boulanger (2008) method is further modified and verified with the liquefaction cases during earthquakes. Additionally, the Iwasaki et al. (1982) method is adopted to compute liquefaction potential index (LPI) at the target locations.

Idriss and Boulanger (2008) use the SPT-N data and geotechnical properties of the soil layers to predict the FOS against the liquefaction for each layer. The cyclic resistance ratio (CRR) of the soils is specified in the system, and the stress (loading) produced in the field as a result of a design earthquake that results in liquefaction is defined as the cyclic stress ratio (CSR). Equation 1 is used to determine the factor of safety against liquefaction:

$$
F O S=\frac{C R R_{7.5}}{C S R} M S F \bullet K_{\sigma}
$$

where $C R R_{7.5}$ is the cyclic resistance ratio calibrated for the earthquake of $M_{\mathrm{w}} 7.5 ; M S F$ is the magnitude scaling factor that accounts for the effects of shaking duration, and $K_{\sigma}$ is a factor for the presence of sustained static shear stresses, such as may exist beneath foundations or within slopes.

$M S F$ and $K_{\sigma}$ were calculated using Eqs. 2 and 3

$$
\begin{aligned}
& M S F=6.9 e^{-\frac{M_{w}}{4}}-0.058(\leq 1.8) \\
& K_{\sigma}=1-C_{\sigma} \ln \left(\frac{\sigma_{v}^{\prime}}{P_{a}}\right) \leq 1.1
\end{aligned}
$$

where

$$
C_{\sigma}=\frac{1}{18.9-2.55 \sqrt{\left(N_{1}\right)_{60 c s}}} \leq 0.3
$$

The SPT-N value derived from the field investigation was used to calculate the CRR, while Eq. 5 was used to correct the raw SPT-N value.

$$
\left(N_{1}\right)_{60}=N C_{N} C_{E} C_{B} C_{R} C_{S}
$$



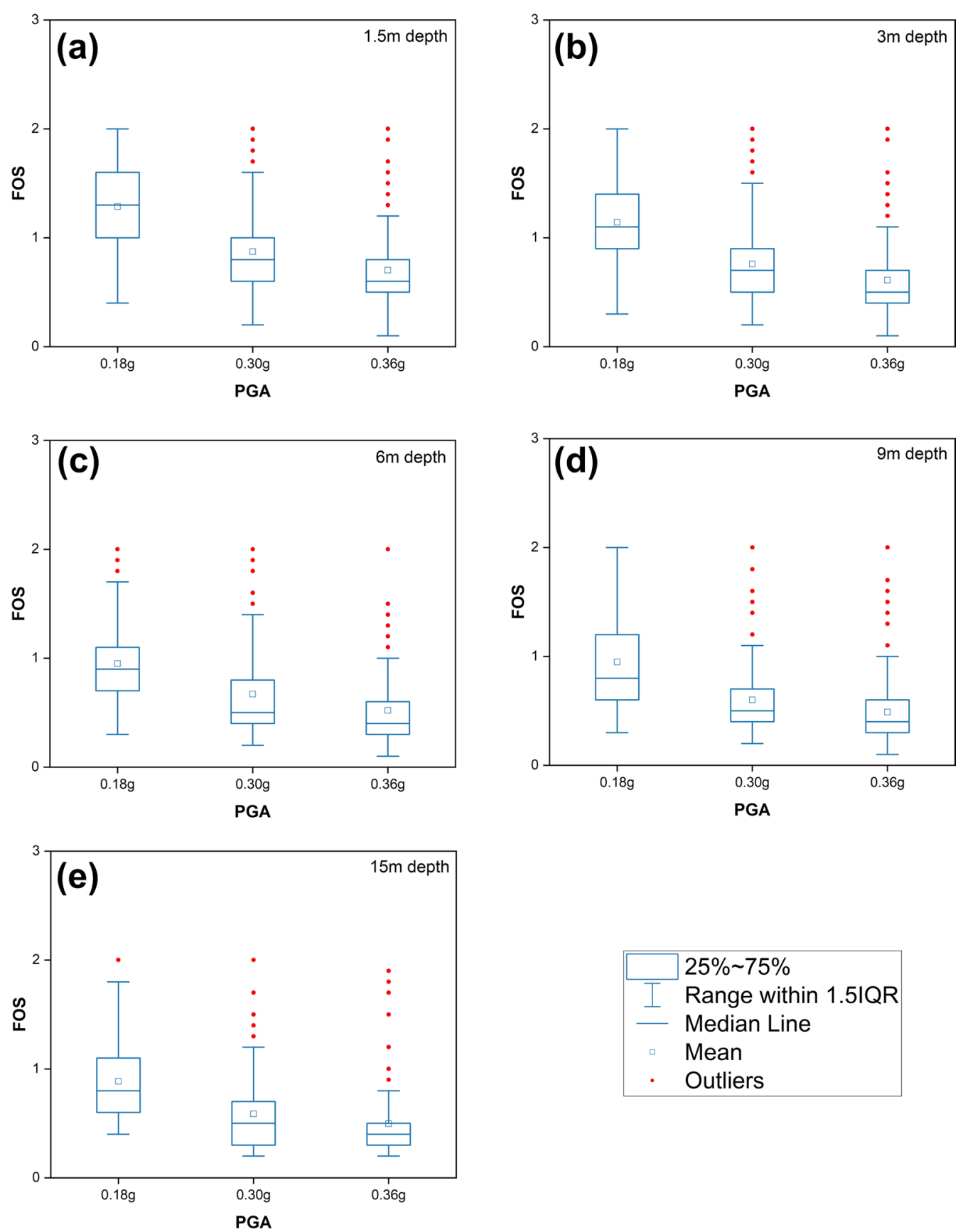

Fig. 7 Box plots of the factor of safety (FOS) against liquefaction for three PGAs at depths of a $1.5 \mathbf{b} 3 \mathbf{c} 6 \mathbf{d} 9$ and $\mathbf{e} 15 \mathrm{~m}$ in the Kathmandu Valley soils

where $\left(N_{1}\right)_{60}$ is the SPT-N normalised to an overburden pressure of $101 \mathrm{kPa}$ (i.e., atmospheric pressure) with a hammer efficiency of $60 \%$. $N$ is the measured SPT blow count. $C_{N}$ is the correction factor for overburden stress. $C_{B}$ is the correction factor for borehole diameter. $C_{E}$ is the correction factor for the hammer energy ratio. $C_{R}$ is the correction factor for rod length. $C_{S}$ is the correction factor for samplers with and without liners.

The $C R R_{7.5}$ is calculated using Eq. 6. 
(a)

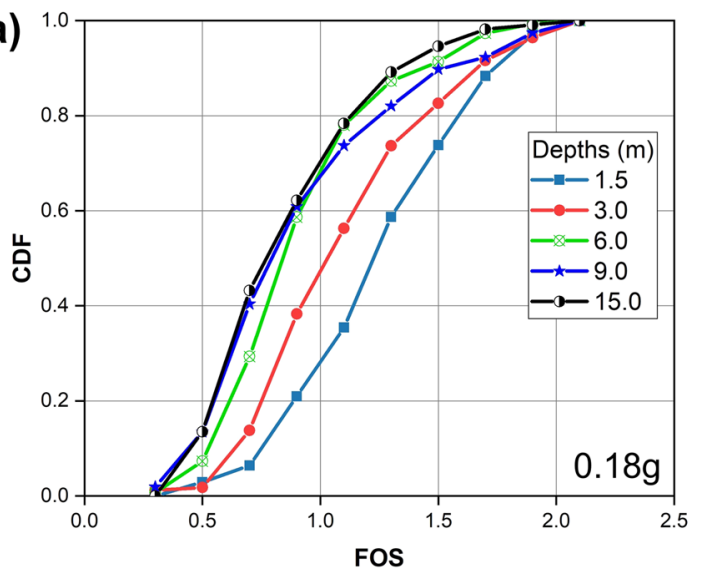

(c)

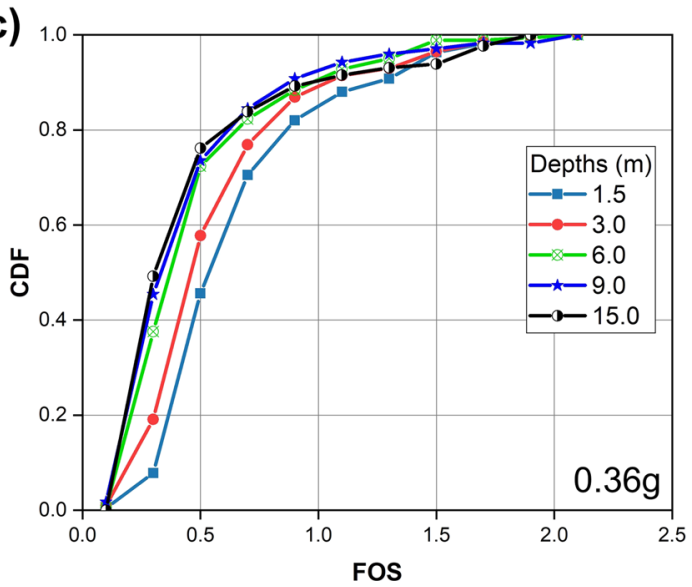

(b)

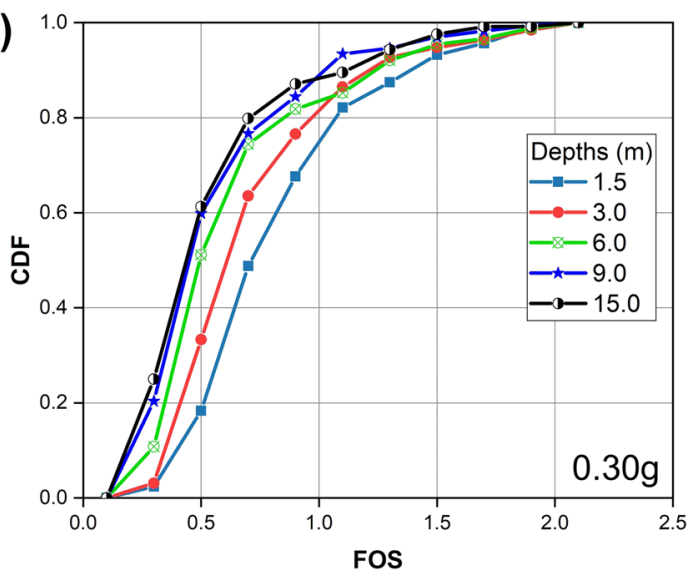

(d)

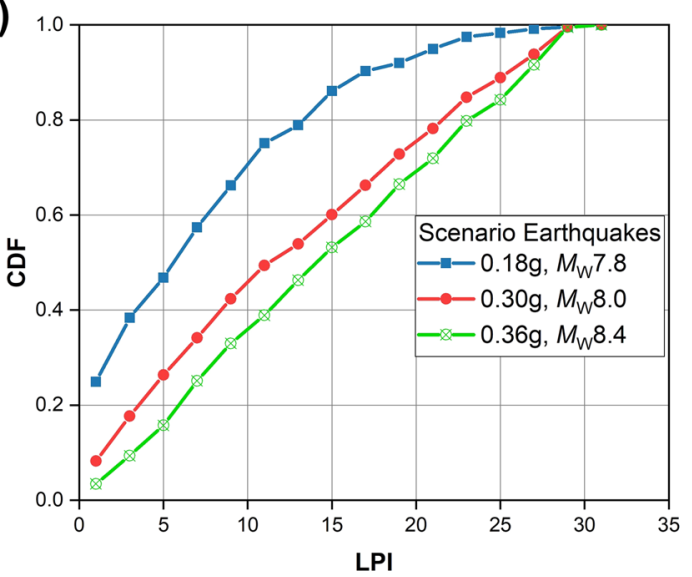

Fig. 8 Cumulative distribution function (CDF) for FOS against liquefaction at PGA of a $0.18 \mathrm{~g}$ b $0.30 \mathrm{~g}, \mathbf{c} 0.36 \mathrm{~g}$ against liquefaction, and d liquefaction potential index (LPI) for three seismic scenarios

$$
\begin{aligned}
C R R_{7.5}= & \exp \left(\frac{\left(N_{1}\right)_{60 c s}}{14.1}+\left(\frac{\left(N_{1}\right)_{60 c s}}{126}\right)^{2}\right. \\
& \left.-\left(\frac{\left(N_{1}\right)_{60 c s}}{23.6}\right)^{3}+\left(\frac{\left(N_{1}\right)_{60 c s}}{25.4}\right)^{4}-2.8\right)
\end{aligned}
$$

where $\left(N_{1}\right)_{60 c s}$ is an equivalent clean-sand SPT blow count.

Equations 7 and 8 are used to calculate $\left(N_{1}\right)_{60 \mathrm{cs}}$ :

$$
\begin{aligned}
& \left(N_{1}\right)_{60 c s}=\left(N_{1}\right)_{60}+\Delta\left(N_{1}\right)_{60} \\
& \Delta\left(N_{1}\right)_{60}=\exp \left(1.63+\frac{9.7}{F C+0.01}-\left(\frac{15.7}{F C+0.01}\right)^{2}\right)
\end{aligned}
$$

where $F C$ is the fines content in the soils obtained from sieve analysis of the borehole or split-spoon samples.

The CSR is calculated by using Eq. 9.

$$
C S R=0.65 \frac{\tau_{\max }}{\sigma_{v c}^{\prime}}=0.65 \frac{\sigma_{v c}}{\sigma_{v c}^{\prime}} \frac{a_{\max }}{g} r_{d}
$$

where $a_{\text {max }}$ is the peak horizontal ground acceleration (PGA) at the ground surface, $g$ is the gravitational acceleration, $\sigma_{v c}$ and $\sigma_{v c}^{\prime}$ are the total overburden stress and effective overburden stress, respectively, and $r_{\mathrm{d}}$ is the stress reduction factor as given in Eq. 10.

$$
\begin{aligned}
r_{d}= & \exp \left[-1.012-1.126 \sin \left(\frac{z}{11.73}+5.133\right)\right. \\
& \left.+M_{w}\left(0.106+0.118 \sin \left(\frac{z}{11.28}+5.142\right)\right)\right]
\end{aligned}
$$

where $z$ is the depth of the soil layer in meters.

\section{Estimation of the liquefaction potential index (LPI)}

The FOS in Eq. 1 above does not help to obtain precise information on the severity of the potential ground deformation at a given depth while the liquefaction potential index (LPI) introduced by Iwasaki et al. (1982) considers 


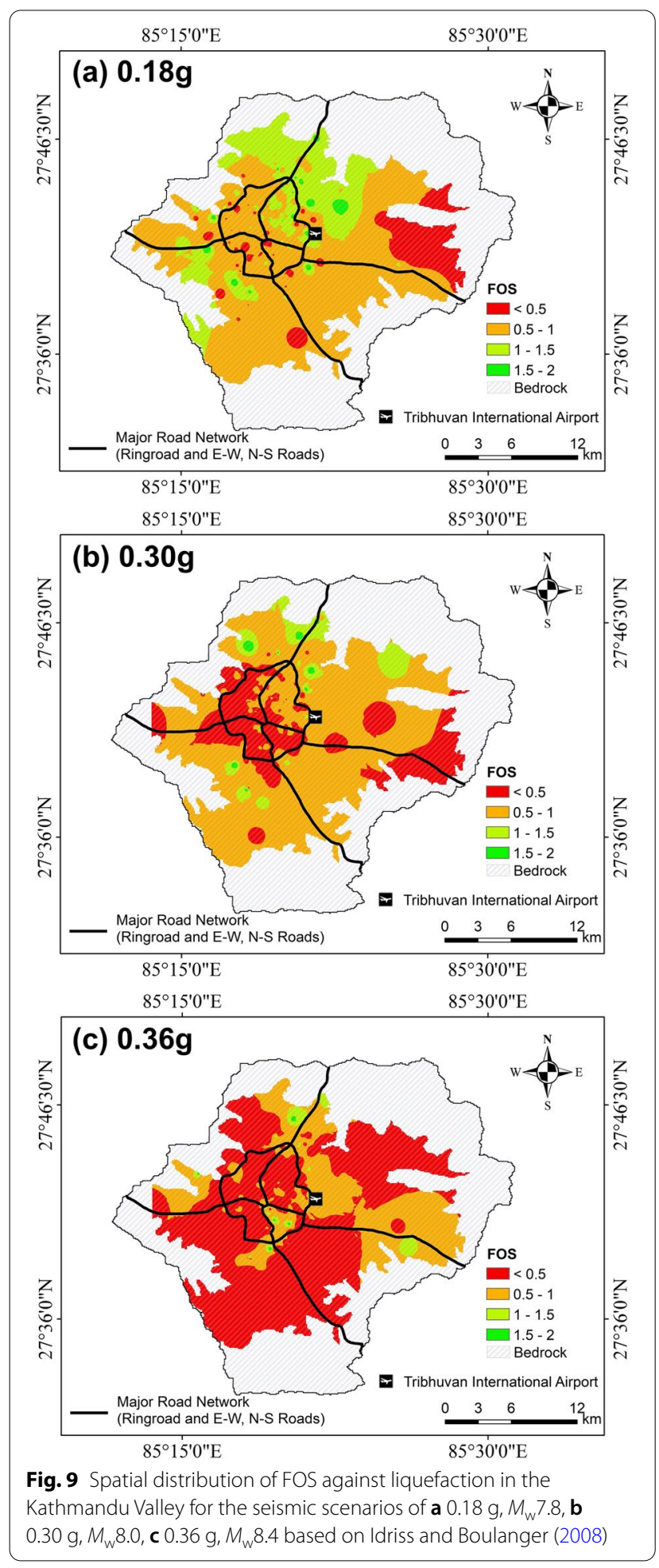

the effect of the liquefiable soil layer's width, depth, and FOS assuming that the severity of liquefaction is proportional to the thickness of the liquefied layer, its proximity to the ground surface, and the extent to which the FOS is less than 1. The LPI is estimated by using Eq. 11 for the top $20 \mathrm{~m}$ or less soil profile (Iwasaki et al. 1982).

$$
L P I=\int_{0}^{z} F(z) W(z) d z
$$

where $z=$ depth of layer; $F(z)=$ function of FOS against liquefaction and is defined as:

$$
\begin{array}{ll}
F(z)=1 & \text { for } \mathrm{FOS} \leq 1 \\
F(z)=0 & \text { for } \mathrm{FOS}>1
\end{array}
$$

$W(z)$ is a depth-weighting factor defined as:

$$
W(z)=10-0.5 z .
$$

Based on the LPI value, the liquefaction sensitivity can be divided into four groups: very low, low, high, and very high.

\section{Estimation of the probability of ground failure (PG)}

For quantitative evaluation, the liquefaction-induced probability of ground failure $\left(P_{\mathrm{G}}\right)$ was estimated using Eq. 15 (Li et al. 2006).

$$
P_{\mathrm{G}}=\frac{1}{1+e^{4.71-0.71 * L P I}}
$$

where $L P I$ is the liquefaction potential index as in Eq. 11 .

\section{Improved SPT-N values}

The $N_{\text {improved }}$ is calculated to provide desired SPT-N after ground improvement ensuring no liquefaction condition. Improved SPT-N values were determined for all liquefiable sites using calculations for desired FOS. Correlations in Eqs. 5, 6, 7, 8, and 9 are used to determine the amount of in-situ soil strength change needed to avoid liquefaction at previously defined liquefiable locations. In case any soil stratum is found to be liquefiable for a known value of CSR, the $C R R_{7.5}^{\text {improved }}$ is calculated using Eq. 16 as follows.

$$
C R R_{7.5}^{\text {improved }}=C S R \times F O S
$$

Then, $\left(N_{1}\right)_{60 c s}$ is evaluated using Eq. 6, and Eqs. 7, 8, and 5 are subsequently used to obtain the final targeted SPT-N (i.e. $N_{\text {improved }}$ ) value. The obtained $N_{\text {improved }}$ values ensure no potential liquefaction with suitable methods of ground improvement needed at liquefaction-prone sites. These values are supposed to prove highly evidential in planning and estimating the cost of ground improvement. 


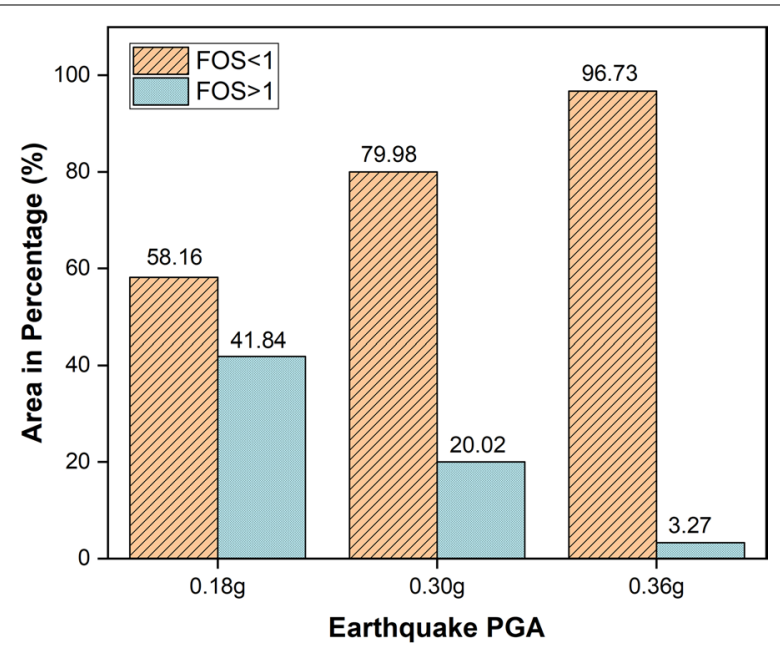

Fig. 10 Area in percentage of FOS against liquefaction in three scenario earthquakes of $M_{w} 7.8(0.18 \mathrm{~g}), M_{w} 8.0(0.30 \mathrm{~g})$, and $M_{w} 8.4$ $(0.36 \mathrm{~g})$

\section{Results and discussions}

To analyze the variation of factor of safety (FOS) values for each substratum encountered at all borehole sites, the box plots of FOS against liquefaction are prepared at depths ranging from 1.5 to $15 \mathrm{~m}$ for the three ground motions of scenario earthquakes as shown in Fig. 7. Box plots are a non-parametric representation of a data set's statistical distribution which depict the minimum, maximum, mean, median, first quartile (25th percentile), and third quartile (75th percentile) of FOS values. The red dots in the figure denote outliers in the FOS dataset. These figures show that the FOS values are estimated to be higher for the earthquake scenario of $M_{\mathrm{w}} 7.8(0.18 \mathrm{~g})$ followed by $M_{\mathrm{w}} 8.0(0.30 \mathrm{~g})$ and $M_{\mathrm{w}} 8.4(0.36 \mathrm{~g})$ for all depths. In all three earthquake scenarios, the $6 \mathrm{~m}$ and $9 \mathrm{~m}$ depths are assessed to be the most vulnerable. The liquefaction vulnerability of these depths may have been exacerbated by the shallow water table of $0.5 \mathrm{~m}$ to $5 \mathrm{~m}$ in these regions. For $M_{\mathrm{w}} 8.4(0.36 \mathrm{~g})$ scenario earthquake, the FOS values were observed to be the lowest at these depths with an interquartile range of 0.3-0.6 and minimum value of 0.1 for both $6 \mathrm{~m}$ and $9 \mathrm{~m}$ depths. However, for the $M_{\mathrm{w}} 8.0(0.30 \mathrm{~g})$ earthquake, the FOS values were found to be the lowest for the depth of $9 \mathrm{~m}$ with interquartile range and minimum value of $0.4-0.7$ and 0.2 , respectively. As expected, for $M_{\mathrm{w}} 7.8(0.18 \mathrm{~g})$ scenario, the FOS values were the highest among the three scenarios with the minimum values of $0.4,0.3,0.3,0.3$ and 0.4 with the corresponding interquartile range of 1-1.6, 0.9-1.4, $0.7-1.1,0.6-1.2$ and $0.6-1.1$ respectively for the depths of $1.5 \mathrm{~m}, 3 \mathrm{~m}, 6 \mathrm{~m}, 9 \mathrm{~m}$ and $15 \mathrm{~m}$.

Moreover, if the median value for a given depth at a particular location is less than one, soil liquefaction is likely to occur at that location (Dixit et al. 2012). In Fig. 7, the median of the FOS values for a given depth tends to be decreasing as the magnitude of the FOS values increases. Similar results of increase in vulnerability of seismic phenomena with their intensification are also reported by Nath et al. (2018) and Dixit et al. (2012).

The FOS profiles were used to compute cumulative distribution functions (CDF) at different depths of 1.5, 3 , 6, 9 and 15 m, which are shown in Fig. 8a-c. The probability of liquefaction susceptibility at a depth for various earthquake magnitudes is depicted in this diagram. Similarly, in Fig. 8d, CDF versus LPI is plotted for three ground motions. Using these distribution functions, the probability of occurrence of liquefaction $(\mathrm{P}(\mathrm{FOS}<1))$ at different depths can be computed.

Figure 8a shows that, for the $M_{\mathrm{w}} 7.8(0.18 \mathrm{~g})$ scenario earthquake, the probability of liquefaction (i.e., FOS $<1$ ) is 0.25 at shallow depth and increases to 0.65 at $15 \mathrm{~m}$ depth. It is interesting to note that the probability of liquefaction is greater than 0.5 at all depths (except for the $1.5 \mathrm{~m}$ depth) up to $15 \mathrm{~m}$ below the ground surface

Table 2 Calculation of FOS-based liquefaction potential index (LPI) using Iwasaki et al. (1982) and probability of ground failure $\left(P_{\mathrm{G}}\right)$ using Li et al. (2006) at Babarmahal (27 $\left.41^{\prime} 39^{\prime \prime} N, 85^{\circ} 19^{\prime} 28^{\prime \prime}\right)$

\begin{tabular}{|c|c|c|c|c|c|c|}
\hline Depth (m) & FOS & $F(z)$ & $W(z)$ & $F(z) * W(z)$ & LPI & $P_{\mathrm{G}}$ \\
\hline 1.5 & 0.4 & 0.5879 & 9.25 & 5.4376 & 10 & 0.93 \\
\hline 3 & 0.5 & 0.5257 & 8.50 & 4.4682 & & \\
\hline 4.5 & 2.0 & 0.0000 & 7.75 & 0.0000 & & \\
\hline 6 & 2.0 & 0.0000 & 7.00 & 0.0000 & & \\
\hline 7.5 & 2.0 & 0.0000 & 6.25 & 0.0000 & & \\
\hline 9 & 2.0 & 0.0000 & 5.50 & 0.0000 & & \\
\hline 10.5 & 2.0 & 0.0000 & 4.75 & 0.0000 & & \\
\hline 12 & 0.96 & 0.0417 & 4.00 & 0.1667 & & \\
\hline 13.5 & 1.34 & 0.0000 & 3.25 & 0.0000 & & \\
\hline 15 & 0.91 & 0.0889 & 2.50 & 0.2223 & & \\
\hline
\end{tabular}



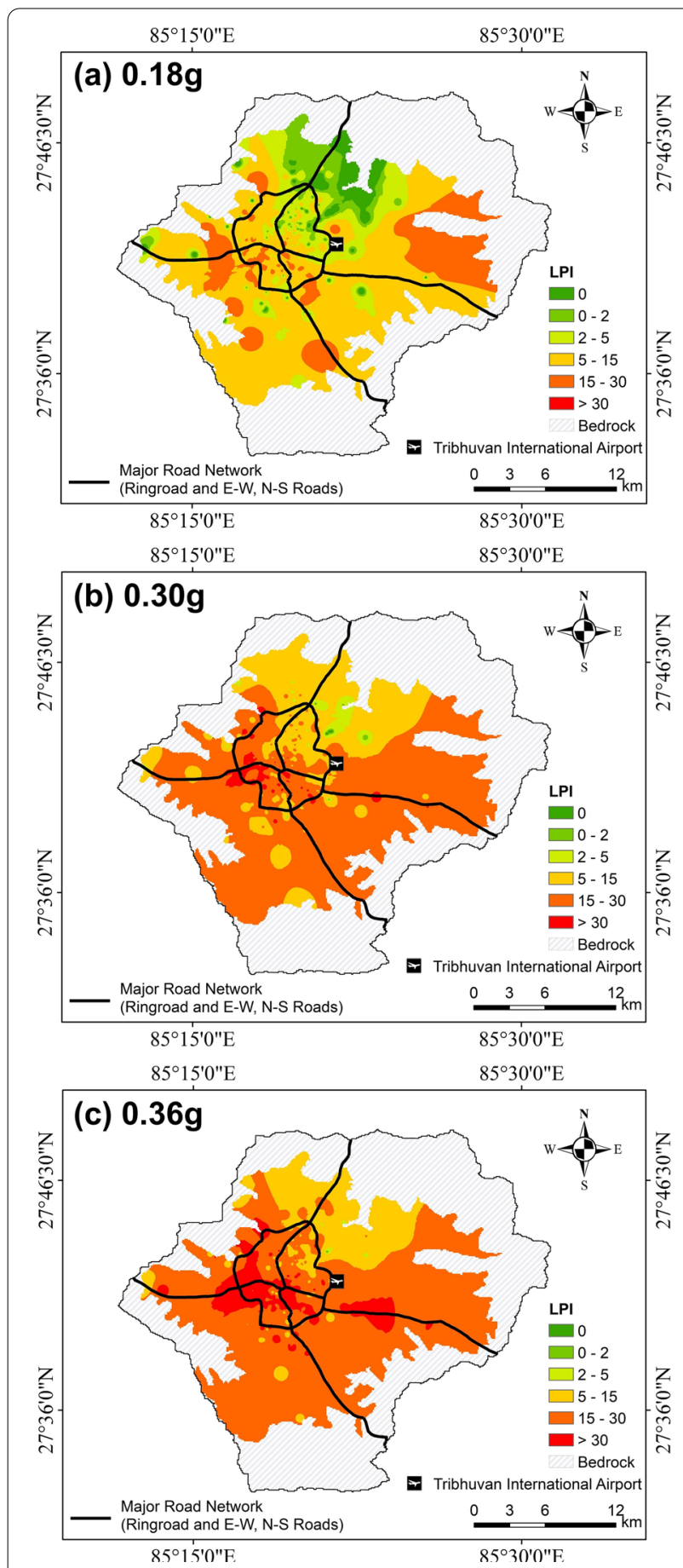

Fig. 11 Liquefaction potential index (LPI) map of the Kathmandu Valley for the seismic scenarios of a $0.18 \mathrm{~g}, M_{\mathrm{w}} 7.8, \mathbf{b} 0.30 \mathrm{~g}, M_{\mathrm{w}} 8.0, \mathbf{c}$ $0.36 \mathrm{~g}, M_{\mathrm{w}} 8.4$ based on Iwasaki et al. (1982)

indicating that the soil is highly susceptible to liquefaction under this earthquake scenario. This is consistent with the occurrence of widespread liquefaction in the Kathmandu Valley during the 2015 Gorkha Earthquake

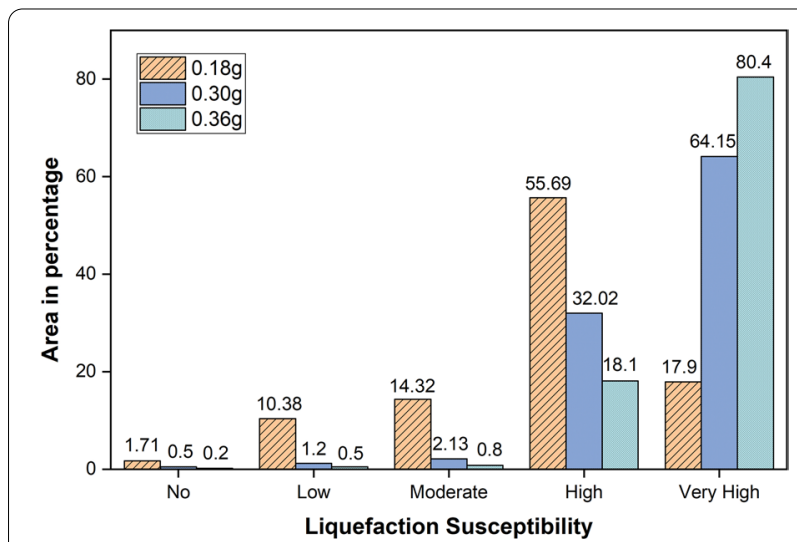

Fig. 12 Area in percentage of liquefaction susceptibility based on liquefaction potential index (LPI) in three scenario earthquakes: $M_{\mathrm{w}} 7.8$ $(0.18 \mathrm{~g}), M_{\mathrm{w}} 8.0(0.30 \mathrm{~g})$, and $M_{\mathrm{w}} 8.4(0.36 \mathrm{~g})$

(Gautam et al. 2017; Sharma and Deng 2019). Moreover, with the increase in magnitude and PGA of the earthquake scenario from Fig. $8 \mathrm{a}-\mathrm{c}$, the probability of liquefaction at all depths has increased significantly, which is in agreement with the findings of Dixit et al. (2012) and Raghu Kanth and Dash (2008).

Figure 9 shows FOS against liquefaction maps for three different seismic scenarios for the Kathmandu Valley. All red-colored areas with FOS $<0.5$ are highly susceptible to liquefaction. Orange-colored areas with $0.5<\mathrm{FOS}<1$ may also be considered susceptible to liquefaction. So, the liquefaction-susceptible areas under the three seismic scenarios are quantitatively summarized in Fig. 10, which indicates that $58.16 \%, 79.98 \%$, and $96.73 \%$ of the study area may liquefy if the ground is shaken during earthquakes with the PGA values of $0.18 \mathrm{~g}, 0.30 \mathrm{~g}$, and $0.36 \mathrm{~g}$ respectively. Observing all the scenarios, almost $80 \%$ of the Kathmandu Valley is found to have FOS less than 1, which means a significant portion of the valley is potentially liquefiable. Gautam et al. (2017), KC et al. (2020), Piya (2004), Sharma et al. (2019), and Subedi et al. (2021) also bring it to the light that the valley has high susceptibility to liquefaction.

Table 2 presents a typical calculation for LPI, and based on the LPI values for all the 410 boreholes, the LPI zonation maps were generated for the Kathmandu Valley considering the three scenario earthquake. The spatial variation of the LPI in the valley is shown in Fig. 11. Severe liquefaction is more likely to occur at locations with an LPI value greater than 15 and is improbable at locations with an LPI value less than 5 (Iwasaki et al. 1982; Sonmez 2003). According to Sonmez (2003), liquefaction potential is very high for LPI $>15$; high for $5<\mathrm{LPI} \leq 15$; moderate for $2<\mathrm{LPI} \leq 5$; low for $0<\mathrm{LPI} \leq 2$ and non-liquefied for LPI $=0$. 


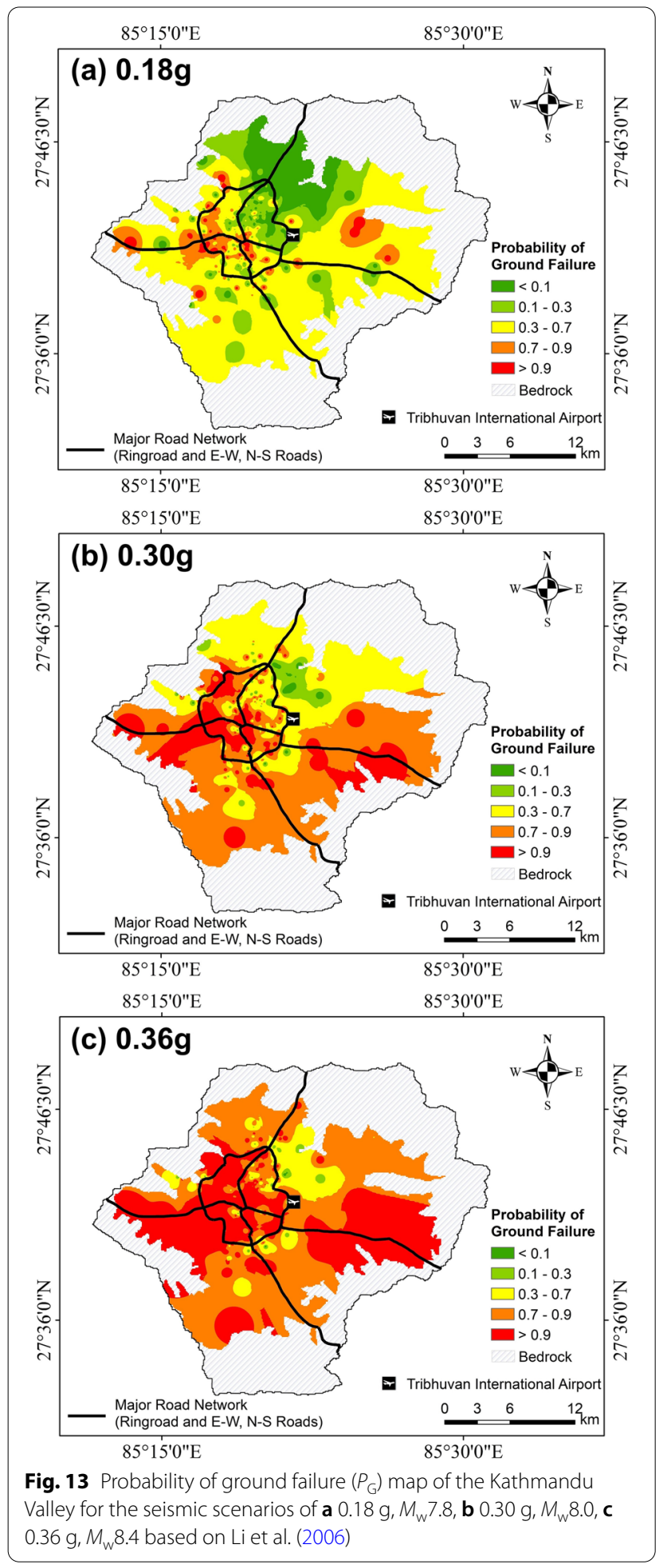

For further interpretation, the prepared maps are studied, and the percentage of locations in the Kathmandu Valley that fall under various liquefaction susceptibility zones is comparatively shown in Fig. 12. The comparative

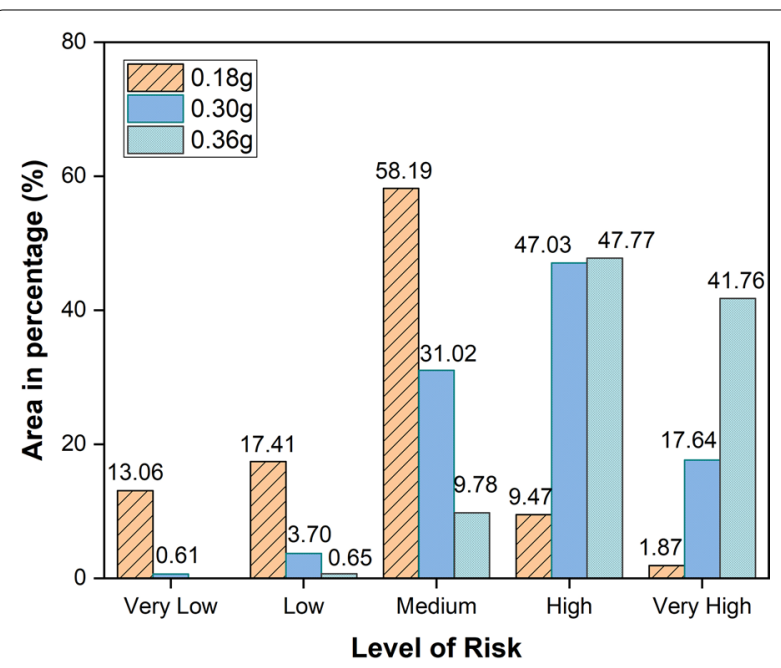

Fig. 14 Area in percentage of the level of risks based on probability of ground failure $\left(P_{\mathrm{G}}\right)$ in three scenario earthquakes of $M_{\mathrm{w}} 7.8(0.18 \mathrm{~g})$, $M_{\mathrm{w}} 8.0(0.30 \mathrm{~g})$, and $M_{\mathrm{w}} 8.4(0.36 \mathrm{~g})$

analysis indicates that $17.9 \%, 64.15 \%$, and $80.4 \%$ of the sample region fall inside a zone with very high liquefaction potential for $0.18 \mathrm{~g}, 0.30 \mathrm{~g}$, and $0.36 \mathrm{~g}$ PGA, respectively. Likewise, $55.69 \%, 32.02 \%$, and $18.1 \%$ of the sample region are located within high liquefaction hazard areas for the aforementioned earthquake scenarios while $14.32 \%, 2.13 \%$, and $0.8 \%$ of the region can be classified as having moderate liquefaction hazard. According to the LPI analysis, $70 \%$ of the study area in the Kathmandu Valley is liquefiable with LPI values greater than 5 , which is in agreement with the results from FOS-based analysis in the preceding part of this study.

The probability of ground failure $\left(P_{\mathrm{G}}\right)$ for each target location, after calculation, interpolation, and mapping, is shown in Fig. 13. The red-colored area indicates a very high risk zone while dark green area indicates a very low risk zone. It was observed that the central and southern parts of the valley have higher risk of ground failure than the northern parts. Within the study area, $1.87 \%$, $17.64 \%$, and $41.76 \%$ of the area are respectively found to be at very high risk of liquefaction-induced ground failure during the scenario earthquakes (i.e., $0.18 \mathrm{~g}, 0.30 \mathrm{~g}$, and 0.36 g PGAs) while $13.06 \%, 0.61 \%$, and $0 \%$ of the area were found to be at very low or no risk of ground failure (Fig. 14). Results from ground failure analysis are consistent with the preceding results based on FOS and LPI.

Furthermore, the resulting maps of liquefaction analysis based on the FOS, LPI, and $P_{\mathrm{G}}$ were compared with the observed liquefaction cases during the 2015 Gorkha Earthquake documented by the authors along with the reports by Okamura et al. (2015); Gautam et al. (2017); and Sharma et al. (2019) as shown in Fig. 15. The FOS, 

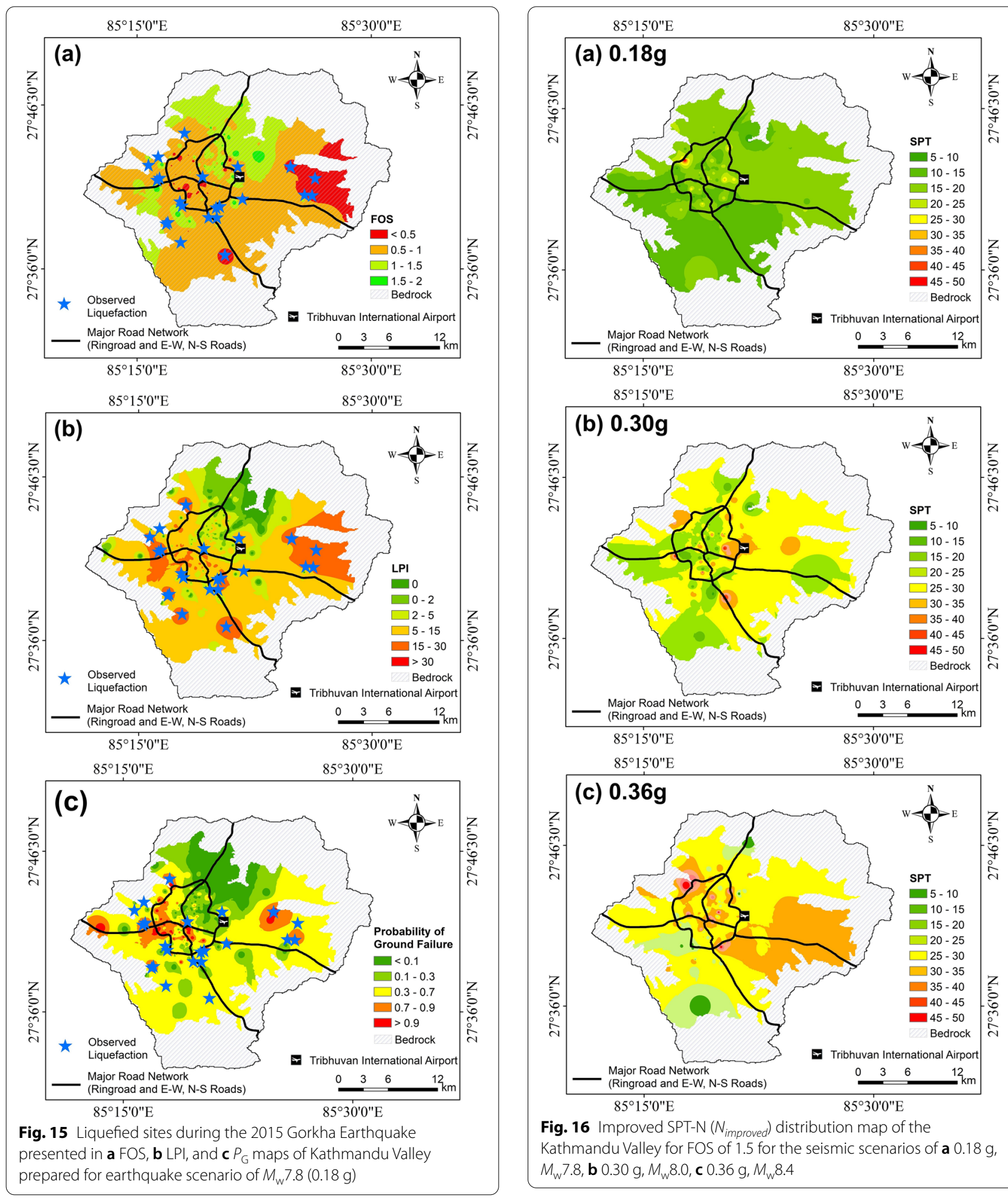

Fig. 16 Improved SPT-N ( $\left.N_{\text {improved }}\right)$ distribution map of the

Kathmandu Valley for FOS of 1.5 for the seismic scenarios of a $0.18 \mathrm{~g}$, $M_{\mathrm{w}} 7.8, \mathbf{b} 0.30 \mathrm{~g}, M_{\mathrm{w}} 8.0, \mathbf{c} 0.36 \mathrm{~g}, M_{\mathrm{w}} 8.4$ 
Table 3 Tabular presentation of calculated FOS, LPI and $P_{\mathrm{G}}$ at liquefaction observed sites during the 2015 Gorkha Earthquake

\begin{tabular}{|c|c|c|c|c|c|c|}
\hline S.N & Location & Latitude & Longitude & FOS & LPI & $P_{\mathrm{G}}$ \\
\hline 1 & Bagdol & $27.6676^{\circ} \mathrm{N}$ & $85.2980^{\circ} \mathrm{E}$ & $0.5-1.0$ & High & Medium \\
\hline 2 & Bungamati & $27.6222^{\circ} \mathrm{N}$ & $85.2622^{\circ} \mathrm{E}$ & $0.5-1.0$ & Very high & High \\
\hline 3 & Changunarayan, NEC & $27.7090^{\circ} \mathrm{N}$ & $85.4140^{\circ} \mathrm{E}$ & $0.5-1.0$ & High & High \\
\hline 4 & Duwakot & $27.7094^{\circ} \mathrm{N}$ & $85.4139^{\circ} \mathrm{E}$ & $<0.5$ & Very high & Very high \\
\hline 5 & Guheshwori & $27.7093^{\circ} \mathrm{N}$ & $85.3576^{\circ} \mathrm{E}$ & $<0.5$ & High & High \\
\hline 6 & Gwarko & $27.6670^{\circ} \mathrm{N}$ & $85.3380^{\circ} \mathrm{E}$ & $<0.5$ & Very high & High \\
\hline 7 & Harisiddhi & $27.6549^{\circ} \mathrm{N}$ & $85.3352^{\circ} \mathrm{E}$ & $<0.5$ & High & Medium \\
\hline 8 & Hattiban & $27.6668^{\circ} \mathrm{N}$ & $85.3344^{\circ} \mathrm{E}$ & $<0.5$ & High & Medium \\
\hline 9 & Imadol & $27.6668^{\circ} \mathrm{N}$ & $85.3383^{\circ} \mathrm{E}$ & $0.5-1.0$ & High & Very high \\
\hline 10 & Itapakhe & $27.6792^{\circ} \mathrm{N}$ & $85.4289^{\circ} \mathrm{E}$ & $<0.5$ & Very high & High \\
\hline 11 & Jharuwarashi & $27.6151^{\circ} \mathrm{N}$ & $85.3439^{\circ} \mathrm{E}$ & $<0.5$ & Very high & Medium \\
\hline 12 & Kamalvinayak & $27.6785^{\circ} \mathrm{N}$ & $85.4370^{\circ} \mathrm{E}$ & $0.5-1.0$ & Very high & High \\
\hline 13 & Khadka Gaon & $27.6950^{\circ} \mathrm{N}$ & $85.2714^{\circ} \mathrm{E}$ & $0.5-1.0$ & very high & High \\
\hline 14 & Lokanthali & $27.6748^{\circ} \mathrm{N}$ & $85.3626^{\circ} \mathrm{E}$ & $<0.5$ & High & Very high \\
\hline 15 & Malpokhari & $27.6720^{\circ} \mathrm{N}$ & $85.2958^{\circ} \mathrm{E}$ & $0.5-1.0$ & Very high & Medium \\
\hline 16 & Manamaiju & $27.7453^{\circ} \mathrm{N}$ & $85.3007^{\circ} \mathrm{E}$ & $0.5-1.0$ & Very high & Very high \\
\hline 17 & Mulpani & $27.7025^{\circ} \mathrm{N}$ & $85.7005^{\circ} \mathrm{E}$ & $0.5-1.0$ & Very high & High \\
\hline 18 & Pakune Pati & $27.6969^{\circ} \mathrm{N}$ & $85.4401^{\circ} \mathrm{E}$ & $<0.5$ & Very high & Medium \\
\hline 19 & Ramkot & $27.7110^{\circ} \mathrm{N}$ & $85.2622^{\circ} \mathrm{E}$ & $<0.5$ & Very high & Medium \\
\hline 20 & Satdobato & $27.6552^{\circ} \mathrm{N}$ & $85.3264^{\circ} \mathrm{E}$ & $<0.5$ & High & High \\
\hline 21 & Singhadurbar & $27.6987^{\circ} \mathrm{N}$ & $85.3200^{\circ} \mathrm{E}$ & $<0.5$ & High & High \\
\hline 22 & Sitapaila & $27.7200^{\circ} \mathrm{N}$ & $85.2726^{\circ} \mathrm{E}$ & $0.5-1.0$ & High & Medium \\
\hline 23 & Syuchatar & $27.6972^{\circ} \mathrm{N}$ & $85.2740^{\circ} \mathrm{E}$ & $0.5-1.0$ & Very high & High \\
\hline 24 & Taudaha 1 & $27.6499^{\circ} \mathrm{N}$ & $85.2829^{\circ} \mathrm{E}$ & $<0.5$ & Very high & High \\
\hline 25 & Taudaha 2 & $27.6484^{\circ} \mathrm{N}$ & $85.2811^{\circ} \mathrm{E}$ & $<0.5$ & Very high & Very high \\
\hline
\end{tabular}

Table 4 Improved SPT-N (N improved ) range for FOS of 1.5 to ascertain no liquefaction during three seismic scenarios i.e., $M_{\mathrm{w}} 7.8(0.18 \mathrm{~g}), M_{\mathrm{w}} 8.0(0.30 \mathrm{~g})$, and $M_{\mathrm{w}} 8.4(0.36 \mathrm{~g})$

\begin{tabular}{lll}
\hline S.N & $\boldsymbol{N}_{\text {improved }}$ range for FOS $=\mathbf{1 . 5}$ & Seismic scenarios \\
\hline 1 & $15-25$ & $0.18 \mathrm{~g}, M_{\mathrm{w}} 7.8$ \\
2 & $20-30$ & $0.30 \mathrm{~g}, M_{\mathrm{w}} 8.0$ \\
3 & $25-35$ & $0.36 \mathrm{~g}, M_{\mathrm{w}} 8.4$ \\
\hline
\end{tabular}

LPI, and $P_{\mathrm{G}}$ values were assessed for liquefied locations using the resulting maps of this study and are presented in Table 3. It is observed that at all the 25 liquefied sites, the FOS values are less than 1, the liquefaction susceptibility varies from high to very high, and the ground failure risk level ranges from medium to very high. This highlights that the findings of this study are coherent with the field observations of liquefaction during the 2015 Gorkha Earthquake.

Figure 16 shows distribution of $N_{\text {improved }}$ values (or the improved SPT-N values), which were determined for all liquefiable sites with FOS value of 1.5 to ensure no liquefaction condition, for the cases of three earthquake scenarios in the valley. As in the case of FOS, LPI, and $P_{\mathrm{G}}$ mapping, the $N_{\text {improved }}$ values assigned to all liquefiable borehole locations in the Kathmandu Valley were mapped. Based on these maps, it is possible to observe $N_{\text {improved }}$ values that ensure no liquefaction situation in potentially liquefiable zones for each of the three earthquake scenarios. Moreover, Table 4 summarises the range of $N_{\text {improved }}$ values that could be obtained with each case with a FOS of 1.5. It is interesting to note that the range of $N_{\text {improved }}$ values obtained in this study is consistent with the results of Khan and Kumar (2020). Selective ground improvement methods may be used to reach the target value of $N_{\text {improved }}$. The adoption of available approaches is conditional on the site requirements and available funds.

\section{Conclusion}

A larger part of the Kathmandu Valley is considered to be highly susceptible to soil liquefaction during seismic activities owing to its geological, geotechnical, and hydrogeological conditions. In this study, we assessed susceptibility, hazard, and risk of liquefaction phenomenon in subsoil stratum of the valley using borehole 
data including SPT-N values and laboratory test parameters. We used factor of safety (FOS) against liquefaction, liquefaction potential index (LPI), and probability of ground failure $\left(P_{\mathrm{G}}\right)$ as the main parameters considering three likely-to-recur scenario earthquakes of $M_{\mathrm{w}} 7.8$ $(0.18 \mathrm{~g}), M_{\mathrm{w}} 8.0(0.30 \mathrm{~g})$ and $M_{\mathrm{w}} 8.4(0.36 \mathrm{~g})$. The obtained results are presented as liquefaction hazard maps showing FOS against liquefaction, assessing liquefaction manifestation in terms of LPI and $P_{\mathrm{G}}$ values. Based on these parameters, the calculated susceptibility of soil liquefaction corroborates with the sites of soil liquefactions observed during the 2015 Gorkha Earthquake. The resulting maps illustrate the quantitative features of the liquefiable layers and the region where ground failure due to liquefaction is likely. The majority of valley ground is found to have medium to very high liquefaction susceptibility and risk. Moreover, the central and southern parts of the valley have higher liquefaction susceptibility and risks than the northern parts.

The FOS, LPI, and $P_{\mathrm{G}}$ distribution maps created in this study enables us to identify liquefaction prone locations in the Kathmandu Valley. Likewise, the liquefaction zonation maps prepared for different scenario earthquakes will help planners and designers in making safe and resilient settlement plans as well as infrastructure development strategies through scientific risk-sensitive land use planning. Moreover, information on liquefaction susceptibility will facilitate structural and geotechnical engineers to make evidence-based decisions on the type of structural foundation. Furthermore, the improved SPT-N $\left(N_{\text {improved }}\right)$ map will assist us in determining the suitable method and extent of ground improvement needed in possible liquefaction susceptible locations in order to ensure no liquefaction.

\section{Acknowledgements \\ The first author acknowledges the financial support received from the Nepal Academy of Science and Technology (NAST) for the PhD Fellowship and the research guidance obtained through the Geo-Engineering and Geoscience Research Accelerator (GeoRA) program from BGC Engineering Inc. (Vancou- ver, Canada). The borehole data and related information used in this work were obtained from various local organizations including Soil Test Pvt. Ltd., Pashupati Drillers, Multi Lab Pvt. Ltd., Clay Engineering, Archiplan Pvt. Ltd., Adarsha Design and Solutions Pvt. Ltd. We acknowledge the help received from Dipendra Gautam (CEO, Interdisciplinary Research Institute for Sustain- ability-IRIS) in acquiring deep borehole data. We also appreciate the help of Rajan K.C. (Post-Graduate Student, Institute of Engineering, Pulchowk Campus, Tribhuvan University) in preparing the maps used in this paper.}

\section{Authors' contributions \\ Conceptualization, MS, and IPA; methodology, MS, and IPA; software, MS; vali- dation, MS, and IPA; formal analysis, MS; investigation, MS; data curation, MS; writing - original draft preparation, MS; writing — review and editing, MS, and IPA; supervision, IPA. All authors read and approved the final manuscript.}

\section{Funding}

The authors did not receive any funding for this research.

\section{Availability of data and materials}

The datasets used and/or analysed during this work are accessible upon reasonable request from the corresponding author.

\section{Declarations}

Competing interests

The authors declare that they have no competing interests.

Received: 19 August 2021 Accepted: 15 December 2021

Published online: 03 January 2022

\section{References}

Ansal A, Tönük G (2007) Source and site factors in microzonation. In: Pitilakis KD (ed) Earthquake geotechnical engineering. Springer, pp 73-92

Ayele A, Woldearegay K, Meten M (2021) A review on the multi-criteria seismic hazard analysis of Ethiopia: with implications of infrastructural development. Geoenviron Disasters 8(1):1-22. https://doi.org/10.1186/S40677020-00175-7/METRICS

Bansal BK, Nath SK (2011) Seismic microzonation handbook, Geoscience divisions. Ministry of Earth Sciences, Government of India

Bolton Seed H, Tokimatsu K, Harder LF, Chung RM (1985) Influence of SPT procedures in soil liquefaction resistance evaluations. J Geotech Eng $111(12): 1425-1445$. https://doi.org/10.1061/(ASCE)0733-9410(1985)111: 12(1425)

Boulanger RW, Idriss IM (2014) CPT and SPT based liquefaction triggering procedures. Report No. UCD/CGM.-14, 1

Bray JD, Sancio RB (2006) Assessment of the liquefaction susceptibility of finegrained soils. J Geotech Geoenviron Eng 132(9):1165-1177. https://doi. org/10.1061/(ASCE)1090-0241(2006)132:9(1165)

Casagrande A (1947) Classification and identification of soils. Proc Am Soc Civ Eng 73(6):783-810

Chaulagain H, Rodrigues H, Silva V, Spacone E, Varum H (2016) Earthquake loss estimation for the Kathmandu Valley. Bull Earthq Eng 14(1):59-88. https:// doi.org/10.1007/s10518-015-9811-5

Chu BL, Hsu SC, Chang YM (2004) Ground behavior and liquefaction analyses in central Taiwan-Wufeng. Eng Geol 71(1):119-139. https://doi.org/10. 1016/S0013-7952(03)00129-7

Dhital M (2015) Geology of the Nepal Himalaya: regional perspective of the classic collided orogen. In: Geology of the Nepal Himalaya: regional perspective of the classic collided orogen. https://doi.org/10.1007/ 978-3-319-02496-7

Dixit J, Dewaikar DM, Jangid RS (2012) Soil liquefaction studies at Mumbai city. Nat Hazards. https://doi.org/10.1007/s11069-012-0154-0

Dixit AM, Yatabe R, Dahal RK, Bhandary NP (2013) Initiatives for earthquake disaster risk management in the Kathmandu Valley. Nat Hazards 69(1):631654. https://doi.org/10.1007/s11069-013-0732-9

Gautam D, de Magistris FS, Fabbrocino G (2017) Soil liquefaction in Kathmandu valley due to 25 April 2015 Gorkha, Nepal earthquake. Soil Dyn Earthq Eng 97:37-47

Gilder CEL, Pokhrel RM, Vardanega PJ (2019) The SAFER borehole database (SAFER/GEO-591_V1.1). University of Bristol

Idriss IM, Boulanger RW (2008) Soil liquefaction during earthquakes. Earthquake Engineering Research Institute

Iwasaki T, Tokida K I, Tatsuoka F, Watanabe S, Yasuda S, Sato H (1982) Microzonation for soil liquefaction potential using simplified methods. In: Proceedings of the 3 rd international conference on microzonation, Seattle, vol 3, no 2, pp 1310-1330

Jalil A, Fathani TF, Satyarno I, Wilopo W (2021) Liquefaction in Palu: the cause of massive mudflows. Geoenviron Disasters 8(1):1-14. https://doi.org/10. 1186/S40677-021-00194-Y

JICA (2002) The study on earthquake disaster mitigation in the Kathmandu Valley, Kingdom of Nepal. In: Japan International Cooperation Agency (JICA) and Ministry of Home Affairs (MOHA), Tokyo

KC A, Sharma K, Pokharel B (2019) Performance of heritage structures during the Nepal earthquake of April 25, 2015. J Earthquake Eng. https://doi.org/ $10.1080 / 13632469.2017 .1360225$ 
KC S, Bhochhibhoya S, Adhikari P, Adhikari P, Gautam D (2020) Probabilistic seismic liquefaction hazard assessment of Kathmandu valley, Nepal. Geomat Nat Hazards Risk 11(1):259-271. https://doi.org/10.1080/19475 705.2020 .1718220

Khan S, Kumar A (2020) Identification of possible liquefaction zones across Guwahati and targets for future ground improvement ascertaining no further liquefaction of such zones. Geotech Geol Eng 38(2):1747-1772. https://doi.org/10.1007/s10706-019-01128-0

KMC (2011) Kathmandu metropolitan city

Kramer SL (1996) Geotechnical earthquake engineering. Pearson Education India

Li DK, Juang CH, Andrus RD (2006) Liquefaction potential index: a critical assessment using probability concept. J GeoEng 1(1):11-24

Moss RE, Seed RB, Kayen RE, Stewart JP, Der Kiureghian A, Cetin KO (2006) CPT-based probabilistic and deterministic assessment of in situ seismic soil liquefaction potential. J Geotech Geoenviron Eng 132(8):1032-1051. https://doi.org/10.1061/(ASCE)1090-0241(2006)132:8(1032)

Mugnier JL, Huyghe P, Gajurel AP, Upreti BN, Jouanne F (2011) Seismites in the Kathmandu basin and seismic hazard in central Himalaya. Tectonophysics 509(1-2):33-49

Naghizadehrokni M, Choobbasti AJ, Naghizadehrokni M (2018) Liquefaction maps in Babol City, Iran through probabilistic and deterministic approaches. Geoenviron Disasters 5(1):1-17. https://doi.org/10.1186/ S40677-017-0094-9/FIGURES/11

Nath SK, Adhikari MD, Maiti SK, Devaraj N, Srivastava N, Mohapatra LD (2014) Earthquake scenario in West Bengal with emphasis on seismic hazard microzonation of the city of Kolkata, India. Nat Hazard 14(9):2549-2575

Nath SK, Srivastava N, Ghatak C, Adhikari MD, Ghosh A, Sinha Ray SP (2018) Earthquake induced liquefaction hazard, probability and risk assessment in the city of Kolkata, India: its historical perspective and deterministic scenario. J Seismol 22(1):35-68. https://doi.org/10.1007/ s10950-017-9691-z

NBC 105 (2020) Seismic design of buildings in Nepal. NBC

Novikova T, Papadopoulos GA, Karastathis V (2007) Evaluation of ground motion characteristics, effects of local geology and liquefaction susceptibility: the case of Itea, Corinth Gulf (Greece). Nat Hazards 40(3):537. https://doi.org/10.1007/s11069-006-9018-9

Okamura M, Bhandary NP, Mori S, Marasini N, Hazarika H (2015) Report on a reconnaissance survey of damage in Kathmandu caused by the 2015 Gorkha Nepal earthquake. Soils Found 55(5):1015-1029. https://doi.org/ 10.1016/j.sandf.2015.09.005

Onder Cetin K, Seed RB, Der Kiureghian A, Tokimatsu K, Harder LF, Kayen RE, Moss S (2004) Standard penetration test-based probabilistic and deterministic assessment of seismic soil liquefaction potential. J Geotech Geoenviron Eng 130(12):1314-1340. https://doi.org/10.1061/(ASCE)10900241(2004)130:12(1314)

Pathak DR, Hiratsuka A, Awata I, Chen L (2009) Groundwater vulnerability assessment in shallow aquifer of Kathmandu Valley using GIS-based DRASTIC model. Environ Geol 57(7):1569-1578. https://doi.org/10.1007/ s00254-008-1432-8

Paudyal YR, Yatabe R, Bhandary NP, Dahal RK (2013) Basement topography of the Kathmandu Basin using microtremor observation. J Asian Earth Sci 62:627-637. https://doi.org/10.1016/j.jseaes.2012.11.011

Piya BK (2004) Generation of a Geological database for the Liquefaction hazard assessment in Kathmandu valley. Geo-Information Science, March, 14

Raghu Kanth STG, Dash SK (2008) Stochastic modeling of SPT N-value and evaluation of probability of liquefaction at Guwahati City. J Earthq Tsunami 2(3):175-196. https://doi.org/10.1142/S1793431108000323

Robertson PK, Wride (Fear) CE (1998) Evaluating cyclic liquefaction potential using the cone penetration test. Can Geotech J 35(3):442-459. https:// doi.org/10.1139/t98-017

Sakai H (2001) Stratigraphic division and sedimentary facies of the Kathmandu Basin Group, central Nepal. J Nepal Geol Soc 25(Sp. Issue):19-32

Seed RB, Cetin KO, Moss RES, Kammerer AM, Wu J, Pestana JM, Riemer MF, Sancio RB, Bray JD, Kayen RE (2003) Recent advances in soil liquefaction engineering: a unified and consistent framework. In: Proceedings of the 26th annual ASCE Los Angeles geotechnical spring seminar, Long Beach, CA

Setiawan H, Serikawa Y, Nakamura M, Miyajima M, Yoshida M (2017) Structural damage to houses and buildings induced by liquefaction in the 2016
Kumamoto Earthquake, Japan. Geoenviron Disasters 4(1):1-12. https:// doi.org/10.1186/S40677-017-0077-X/FIGURES/20

Setiawan H, Serikawa Y, Sugita W, Kawasaki H, Miyajima M (2018) Experimental study on mitigation of liquefaction-induced vertical ground displacement by using gravel and geosynthetics. Geoenviron Disasters 5(1):1-9. https://doi.org/10.1186/S40677-018-0115-3/FIGURES/10

Sharma K, Deng L (2019) Reconnaissance report on geotechnical engineering aspect of the 2015 Gorkha, Nepal, earthquake. J Earthq Eng 23(3):512-537

Sharma K, Deng L, Noguez CC (2016) Field investigation on the performance of building structures during the April 25, 2015, Gorkha earthquake in Nepal. Eng Struct 121:61-74. https://doi.org/10.1016/j.engstruct.2016. 04.043

Sharma K, Subedi M, Acharya I, Pokharel B (2018) Geotechnical and structural aspect of 2015 Gorkha Nepal earthquake and lesson learnt. J Inst Eng 13(1):20-36. https://doi.org/10.3126/jie.v13i1.20345

Sharma K, Deng L, Khadka D (2019) Reconnaissance of liquefaction case studies in 2015 Gorkha (Nepal) earthquake and assessment of liquefaction susceptibility. Int J Geotech Eng 13(4):326-338

Shrestha S, Semkuyu DJ, Pandey VP (2016) Assessment of groundwater vulnerability and risk to pollution in Kathmandu Valley, Nepal. Sci Total Environ 556:23-35. https://doi.org/10.1016/j.scitotenv.2016.03.021

Sonmez H (2003) Modification of the liquefaction potential index and liquefaction susceptibility mapping for a liquefaction-prone area (Inegol, Turkey). Environ Geol 44(7):862-871

Subedi M, Sharma K, Upadhayay B, Poudel RK, Khadka P (2013) Soil liquefaction potential in Kathmandu Valley. Int J Landslide Environ 1(1):91-92

Subedi M, Sharma K, Acharya IP, Adhikari K (2018) Soil liquefaction in Kathmandu Valley due to 2015 Gorkha, Nepal Earthquake and assessment of liquefaction susceptibility. In: 11th national conference on earthquake engineering

Subedi M, K.C. R, Acharya IP (2021) SPT-based seismic soil liquefaction potential evaluation of Kathmandu Valley using first-order second-moment method. In: GeoNiagara 2021, Canada

Thapa DR (2018) Seismicity of Nepal and the surrounding region. Bull Dept Geol 12:83-86. https://doi.org/10.3126/BDG.V2010.20727

Tsuchida H, Hayashi S (1972) Estimation of liquefaction potential of sandy soils. Mcgraw Hill Book Company, p 14

UNDP (1994) Seismic hazard mapping and risk assessment for Nepal

Yilmaz I, Bagci A (2006) Soil liquefaction susceptibility and hazard mapping in the residential area of Kütahya (Turkey). Environ Geol 49(5):708-719

Yoshida N (1990) Damage to foundation piles and deformation pattern of ground due to liquefaction-induced permanent ground deformations. In: Proceedings of the 3rd Japan-US workshop on earthquake resistant design of lifeline facilities and countermeasures for soil liquefaction, pp 147-161

\section{Publisher's Note}

Springer Nature remains neutral with regard to jurisdictional claims in published maps and institutional affiliations.

\section{Submit your manuscript to a SpringerOpen ${ }^{\circ}$ journal and benefit from:}

- Convenient online submission

- Rigorous peer review

- Open access: articles freely available online

- High visibility within the field

Retaining the copyright to your article

Submit your next manuscript at springeropen.com 